\title{
El control de los agregados monetarios: lecciones y experiencias del caso venezolano reciente ${ }^{1}$
}

\author{
Leonardo V. Vera ${ }^{2}$
}

\begin{abstract}
Resumen
Este trabajo intenta exponer las dificultades que confronta la autoridad monetaria para ejercer algún grado de control sobre los agregados monetarios, y para ello evalúa la experiencia reciente de una economía abierta y dependiente de un recurso mineral exportable como Venezuela. El trabajo no sólo expone argumentos analíticos, sino además provee evidencia muy sencilla en demostración de que existen numerosas fuentes de endogeneidad de la base monetaria, del multiplicador y de otros agregados más amplios en la economía venezolana. Aunque el Banco Central en Venezuela no viene anunciando ni explicando públicamente la estrategia y el alcance de la política monetaria, el trabajo muestra que la autoridad monetaria se ha movido sigilosamente, en los últimos tiempos, hacia una estrategia de uso de las tasas marcadores de las operaciones de mercado abierto como variable operativa buscando un objetivo final de actividad económica.
\end{abstract}

Palabras claves: Política monetaria; Venezuela; Base monetaria; Endogenidad del dinero.

\section{Abstract \\ The control of monetary aggregates: lessons and experiences from the recent Venezuelan case}

This work examines the difficulties and formidable challenges faced by monetary authorities to control the behavior of monetary aggregates in an open economy dependent of an exportable natural resource such as Venezuela. The work not only introduces analytical arguments but also provides some empirical evidence that shows the several sources of endogeneity in the monetary base, the multiplier and other wider monetary aggregates in Venezuela. Though the Central Bank currently does not announce a clear strategy and target for the practice of monetary policy, we argue that the monetary authority has recently moved towards a strategy of targeting short-term interest rates. Presumably, the use of the repo rate as a monetary policy instrument is tied to a final target of economic activity.

Key words: Monetary policy; Venezuela; Monetary base; Endogenous money.

JEL E40, E51, E52.

\section{Introducción}

El término "política monetaria" es a menudo descrito y entendido como el manejo que ejerce alguna autoridad monetaria sobre la cantidad de dinero con el propósito de controlar la inflación y preservar el valor de la moneda. Esta es la

(1) El autor quiere agradecer los útiles comentarios y sugerencias hechos por dos árbitros anónimos. Las limitaciones restantes son enteramente responsabilidad del autor.

(2) Profesor de la Universidad Central de Venezuela, FACES, Escuela de Economía, Ciudad Universitaria, Caracas, Venezuela. E-mail: <leonardo.vera@cantv.net>. 
forma en que Harry Johnson (1962), en uno de sus trabajos más clásicos, definía hace más de 40 años atrás la política monetaria. Esa es, si se quiere, la forma, en que todavía se define hoy la política monetaria en la gran mayoría de los manuales de macroeconomía y teoría monetaria. En una referencia más reciente, Rasche y Williams (2005, p. 2) nos recuerdan que la política monetaria sigue interpretándose como "la acción de influenciar alguna medida del stock de dinero". Sachs y Larrain (1994), uno de los textos más populares de macroeconomía en occidente, señala en forma precisa: "Controlar la oferta monetaria es... la tarea crucial del Banco Central”' (p. 273)

Esta forma de entender la política monetaria ha resistido los embates del tiempo, incluso contra la influencia de otras formas innovadoras de interpretar la relación existente entre los mercados financieros y los mercados reales, contra nuevas fórmulas a partir de las cuales los bancos centrales reaccionan y procuran incidir sobre las decisiones económicas y financieras del público, y contra un cúmulo de evidencias que ponen en duda el grado de influencia que eventualmente pueden ejercer los bancos centrales sobre la economía real o sobre los precios. En cualquier caso, y como deja entrever la visión convencional, si la política monetaria fuera estrictamente un asunto de control de los agregados monetarios en la consecución de un objetivo, la pregunta inmediata que se presenta es ¿cuál debe entonces ser ese objetivo? La respuesta frecuente es "la inflación". De hecho la ola de cambios institucionales por las que pasan muchas economías emergentes alrededor de las leyes de bancos centrales, declarando explícitamente la "estabilidad de precios" como el objetivo central de la autoridad monetaria y otorgándole mayor autonomía al organismo con el fin de evitar desviaciones de ese objetivo, constituye un sub-producto de esa extendida visión convencional que señala: "la inflación es, en todo momento y en todo lugar, un fenómeno monetario" y "la cantidad de dinero es algo que está bajo el control de las autoridades monetarias".

Pero basta con sumergirse un tanto en las turbulentas aguas por las que fluye la literatura monetaria o echar un vistazo al proceder de muchos bancos centrales para percatarse que el asunto puede ser algo más complejo. Sucede que los bancos centrales actúan a menudo como si tuvieran un mandato dual, atendiendo al nivel de actividad económica también como un objetivo (y en ocasiones atendiendo a múltiples objetivos) si las circunstancias así lo requieren. Así mismo, numerosos estudios indican, cada vez con más claridad, que al menos en el corto plazo la relación entre los agregados monetarios y el nivel de precios es difusa y que de existir alguna relación entre la variación de los agregados monetarios y la variación en los precios, esta estaría ceñida estrictamente al largo plazo (ver Christiano et al., 1999, para un resumen de esta discusión). Tampoco es 
trivial que la política monetaria en las economías en desarrollo deba ocuparse sólo del control de la inflación (ver Epstein 2003, para esta discusión) y los canales de transmisión, sean estos a través de los agregados o a través de las tasas, a menudo no funcionan adecuadamente.

La discusión en torno al alcance y el proceder de la política monetaria es en la actualidad muy relevante en Venezuela. La economía venezolana exhibe, en los últimos tres años, un crecimiento muy importante en todos los agregados monetarios. La base monetaria, constituida por la cantidad de monedas y billetes emitidos por la autoridad monetaria más las reservas de los bancos depositados en el Banco Central, se ha expandido a un promedio interanual de $51 \%$ entre Enero de 2003 y noviembre de 2005, duplicándose a lo largo del año 2006. Patrones de expansión similares muestran agregados más amplios como M1 y M2, incluso en términos reales. De hecho la liquidez real, M2, alcanzó en 2005 el nivel más elevado desde el año 1991 (Banco Mercantil, 2006). En este contexto surgen, casi que en forma natural, un número de interrogantes: ¿Qué razón o razones explican este giro expansivo en el dinero base y en los agregados más amplios? ¿Tiene esto algo que ver con la conducta de la autoridad monetaria? ¿Acaso la autoridad monetaria ejerce o no algún control sobre los agregados monetarios en Venezuela?

Este trabajo pretende avanzar algunas impresiones al respecto revisando el comportamiento de las series estadísticas así como el marco sobre el cual se ha formulado la política monetaria reciente en Venezuela. En la sección que sigue se presenta una panorámica de la evolución de ciertas series monetarias mensuales en Venezuela con el propósito de establecer indicios en torno al control de los agregados, incluso bajo períodos donde se presupone una firme determinación del Banco Central por ejercer cierto control sobre estos. Nuestro análisis se ubica en el período que va desde finales de los años ochenta hasta finales del año 2005. Conviene observar que, justamente durante buena parte de ese lapso, Arreaza, Ayala y Fernández (2001) han señalado "que la política monetaria en Venezuela ... se ha fundamentado en una programación financiera orientada hacia el control de agregados monetarios" (p. 5). La sección 2 se centra en recoger los argumentos analíticos que podrían explicar la pérdida de control sobre los agregados en este período. Estos argumentos no están expuestos en un sentido estrictamente genérico o abstracto, sino que han sido considerados tomando en cuenta el contexto económico e institucional del sistema monetario en Venezuela. En la sección 3, se pretende cotejar, para el caso venezolano, cada uno de los argumentos presentados en la sección 2 con cierta evidencia empírica muy simple y bastante preliminar al respecto. Finalmente, la sección 4 intenta responder a la pregunta sobre que variable podría estar hoy día bajo el control de la autoridad monetaria. Específicamente, nos hemos remitido a revisar la conducta de la 
autoridad monetaria bajo lo que comenzó a llamarse desde el año 2002 la 'estrategia monetaria flexible', donde el objetivo de política parece haberse orientado al estímulo de la actividad económica.

\section{El control de los agregados monetarios: los indicios}

Numerosos estudios previos sobre la conducta de la política monetaria en Venezuela convienen en señalar que a partir del año 1989, en el marco de un acuerdo de financiamiento ampliado con el Fondo Monetario Internacional y apoyado por el Banco Mundial, la política monetaria da un giro importante con la instrumentación de los llamados "programas monetarios" (ver por ejemplo, Diaz y d'Empaire 1992, y Mirabal 1999). Desde entonces, el uso de las operaciones de mercado abierto con bonos emitidos por la autoridad monetario se convirtió en una innovación y en esencia la tarea del Banco Central se enfocó en mantener en línea el comportamiento del dinero base con los objetivos de estabilidad macroeconómica. Pero el historial económico de la década de los años noventa difícilmente puede reclamar un sitial privilegiado en materia de estabilidad económica para Venezuela y, a decir verdad, los primeros años de la década siguiente tampoco dieron razones para el optimismo en esta materia. Durante este período de casi 15 años la economía venezolana estuvo expuesta a las secuelas de dos intentos de Golpe de Estado en el año 1992 y a una aventura similar en el año 2002. Así mismo, la mayor crisis financiera que haya conocido el país se desató en el año 1994 y sus secuelas persistieron por un buen tiempo. Por si fuera poco, los ciclos de precios del mercado petrolero se hicieron más intensos amplificando la inestabilidad macroeconómica. En buena parte, las consecuencias sobre el desempeño macroeconómico de este historial se sintetiza en el Cuadro 1. Ahí puede apreciarse que, entre 1989 y 2005, la tasa inflación anual en Venezuela siempre remontó los dos dígitos y que a pesar de la apreciable disminución ocurrida hacia el final del período, en promedio estuvo en casi $40 \%$. Los ajustes recurrentes, y en algunos casos dramáticos, de la paridad cambiaria, en un contexto de elevada inflación, fueron típicos, y la tasa de crecimiento promedio del PIB por habitante fue virtualmente igual a cero (con una enorme desviación de casi 7 puntos porcentuales).

Si la visualización se circunscribe al comportamiento de los agregados monetarios La Figura 1 muestra, sobre el mismo horizonte temporal, que la variación porcentual mensual de las series de dinero base, del circulante M1 y de la liquidez M2 (una vez desestacionalizadas), no reflejan de forma alguna la consecución de una regla de crecimiento estable de las agregados. En contraste, las series para estas variables monetarias presentan, más bien, grandes fluctuaciones con cuatro fases expansivas y con co-movimientos muy estrechos a lo largo del 
período 1991-2005. La última de estas fases de expansión comienza a mediados de 2002, y sin ser la más intensa, si parece ser la más prolongada.

\section{Cuadro 1}

Venezuela: evolución de los precios, el tipo de cambio y el PIB per capita

\begin{tabular}{|l|c|c|c|c|}
\hline Año & $\begin{array}{c}\text { Tasa de } \\
\text { inflación anual } \\
(\%)\end{array}$ & $\begin{array}{c}\text { Tipo de cambio } \\
\text { nominal } \\
\text { promedio } \\
\text { (Bs/US\$) }\end{array}$ & $\begin{array}{c}\text { Depreciación } \\
\text { anual del tipo de } \\
\text { cambio }\end{array}$ & $\begin{array}{c}\text { Tasa de } \\
\text { crecimiento del } \\
\text { PIB per-capita } \\
(\%)\end{array}$ \\
\hline 1989 & 84.46 & 38,95 & 98.72 & -10.89 \\
\hline 1990 & 40.66 & 47,44 & 21.80 & 2.64 \\
\hline 1991 & 34.21 & 57,32 & 20.83 & 7.22 \\
\hline 1992 & 31.42 & 69,03 & 20.43 & 3.69 \\
\hline 1993 & 38.12 & 91,15 & 32.04 & -1.92 \\
\hline 1994 & 60.82 & 148,89 & 63.36 & -4.44 \\
\hline 1995 & 59.92 & 176,85 & 18.78 & 1.78 \\
\hline 1996 & 99.88 & 417,34 & 135.99 & -2.23 \\
\hline 1997 & 50.04 & 488,59 & 17.07 & 4.26 \\
\hline 1998 & 35.78 & 547,55 & 12.07 & -1.65 \\
\hline 1999 & 23.57 & 605,70 & 10.62 & -7.76 \\
\hline 2000 & 16.21 & 679,93 & 12.26 & 1.80 \\
\hline 2001 & 12.53 & 723,67 & 6.43 & 1.50 \\
\hline 2002 & 22.43 & 1160,95 & 60.43 & -10.50 \\
\hline 2003 & 31.09 & 1608,63 & 38.56 & -9.35 \\
\hline 2004 & 21.75 & 1885,49 & 17.21 & 15.81 \\
\hline 2005 & 15.95 & 2111,7 & 12.00 & 7.48 \\
\hline Promedio 1989-2005 & 39.93 & & 35.21 & -0.15 \\
\hline Desviación Estandard & 23.65 & & 34.47 & 6.91 \\
\hline Fun & & & \\
\hline
\end{tabular}

Fuente: Datos del BCV, INE y Cálculos propios.

¿Qué pudiera estar originando, por ejemplo, las fases expansivas en los agregados? Un análisis un tanto descontextualizado de la realidad económica venezolana diría, en principio, que pueden ser tanto el resultado de choques sobre la oferta como sobre la demanda de dinero. Si nos ceñimos a la oferta monetaria, aún podríamos afirmar que pudieran ser choques o innovaciones de oferta provocados por la acción del Banco Central (con algún propósito de política quizás), o choques exógenos producidos por eventos no vinculados a los instrumentos típicos de intervención de la autoridad monetaria. 
Figura 1

Variación porcentual de los agregados monetarios en Venezuela

1991: 1-2005: 10

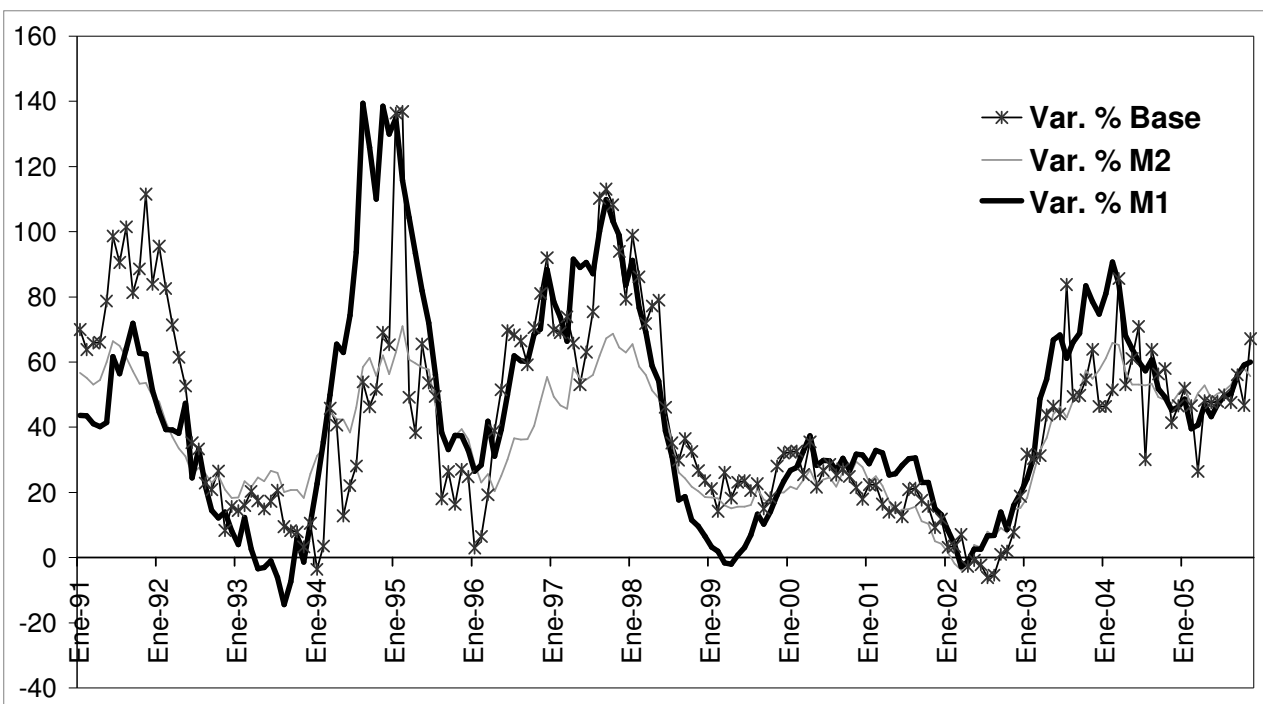

Fuente: Banco Central de Venezuela.

Al poner esta imagen en contexto, la explicación que atribuye estos choques a eventos no necesariamente vinculados con el manejo en instrumentos tradicionalmente utilizados por el Banco Central, cobra cierto valor. ${ }^{3}$ Veamos porqué. La expansión monetaria del 91, por ejemplo, parece ser un reflejo de los mayores ingresos petroleros recibidos por la economía en ese lapso; la expansión entre el 94-95, por su parte, es consistente con la política de auxilios financieros concedidos a la banca a través del Fondo de Garantía de Depósitos (Fogade) tanto como con la instrumentación de un control de cambios (que fenecería a mediados de 1996); la expansión del año 1996-1997 recoge un nuevo ciclo de auge en los ingresos petroleros, y la que se reporta ya firmemente desde el año 2003 corresponde a un ciclo de precios petroleros altos en medio de un nuevo régimen administrado de divisas. Aún admitiendo que el Banco Central haya hecho uso de sus instrumentos típicos de intervención de política monetaria con un propósito firme de expandir los agregados, ${ }^{4}$ habría que dilucidar si efectivamente estas acciones de política ejercieron una influencia más decisiva en el comportamiento expansivos de los agregados, que los eventos de naturaleza más estocástica como los que hemos mencionado. Pero curiosamente el comportamiento y el registro

(3) Tradicionalmente son las operaciones de mercado abierto, las operaciones de descuento, las modificaciones en el encaje obligatorio y las operaciones cambiarias, los instrumentos o mecanismos indirectos a partir de los cuales, genéricamente, el Banco Central puede incidir sobre su variable de objetivo intermedio.

(4) Tales como: cambios agresivos a la baja en el volumen de encajes legales, operaciones de mercado abierto de corte expansivo, o variaciones en las tasas de descuento hacia la baja. 
estadístico de lo que pudo ser la política monetaria del Banco Central durante estos episodios parece decir otra cosa.

El Figura 2 brinda una panorámica del comportamiento que muestra la razón entre el stock de instrumentos usados por el Banco Central para hacer sus operaciones de mercado abierto contra la base monetaria; en esencia, dos variables de acervo. A nuestro juicio este es un buen indicador del tenor que toma la política monetaria en Venezuela, considerando como señalan Arreaza, Ayala y Fernández (2001, p. 3) que, “en 1989 las operaciones de mercado abierto pasaron a ser el instrumento de política preponderante". Lo sorprendente del Figura 2 es que esta serie se mueve con un alto grado de correspondencia con la variación porcentual de M1. De hecho el coeficiente de correlación entre las series es positivo $(+0,67)$, lo que indica entre otras cosas y sin ambigüedad alguna, que el Banco Central intentó restringir la oferta de dinero justo en las fases de expansión de los agregados. En efecto, la figura revela que el Banco Central ha intentado hacer esto en todos y cada uno de los episodios expansivos, sin mucho éxito desde luego. Resultados casi idénticos se obtienen al hacer el mismo contraste con M2 en lugar del circulante.

Figura 2

Razón saldo en OMA/Base Monetaria y Var. \% en M1

1991: 1-2005: 10

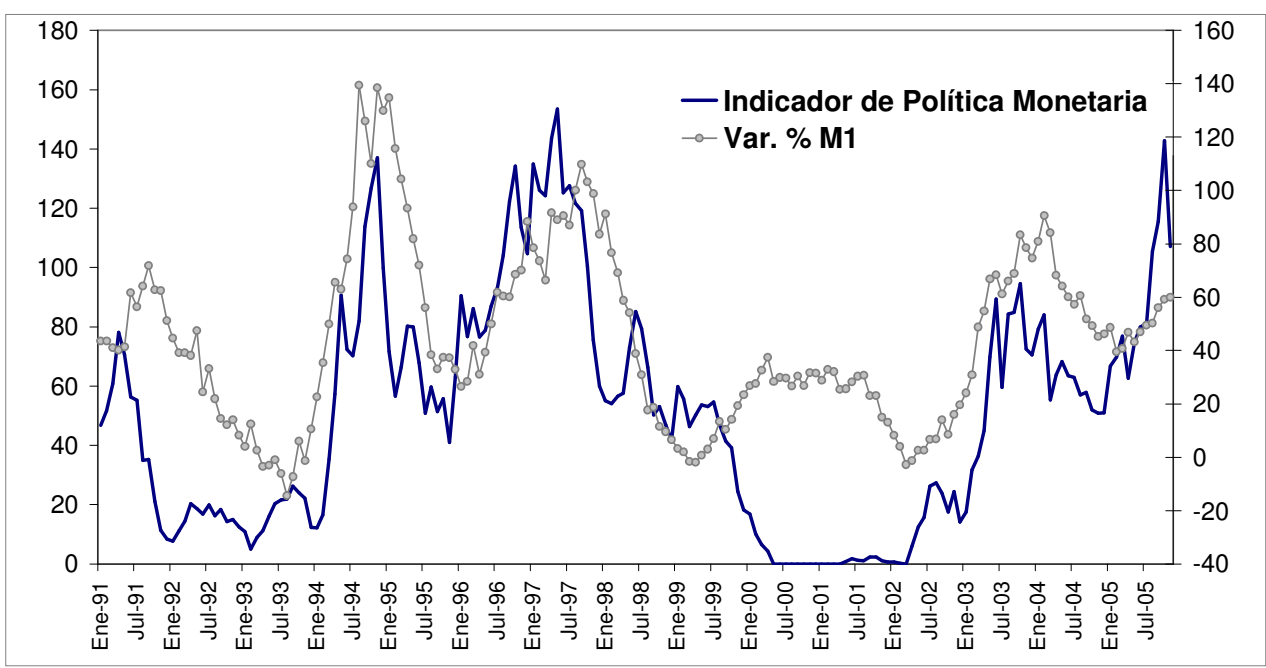

Fuente: Banco Central de Venezuela y Cálculos propios.

Conviene señalar, no obstante, que el contraste entre la variación porcentual de M1 y la evolución del encaje regulatorio recoge algo mejor la incidencia de la política monetaria sobre los agregados. El Figura 3 permite apreciar que los ajustes al alza en el encaje regulatorio ocurridos en el año 1991 y en el año 1997 
preceden ulteriores bajas en la variación de M1. En ambas ocasiones la elevación del encaje parece haberse utilizado como un mecanismo complementario a las operaciones de mercado abierto. El informe del Banco Central del año 1991 lo expresa de la siguiente forma: "Para reforzar las operaciones de mercado abierto, se utilizó el mecanismo de encaje legal como instrumento de control monetario" (p. 32).

Figura 3

Variación \% en M1 y encaje leal, 1991: 1-2005: 12

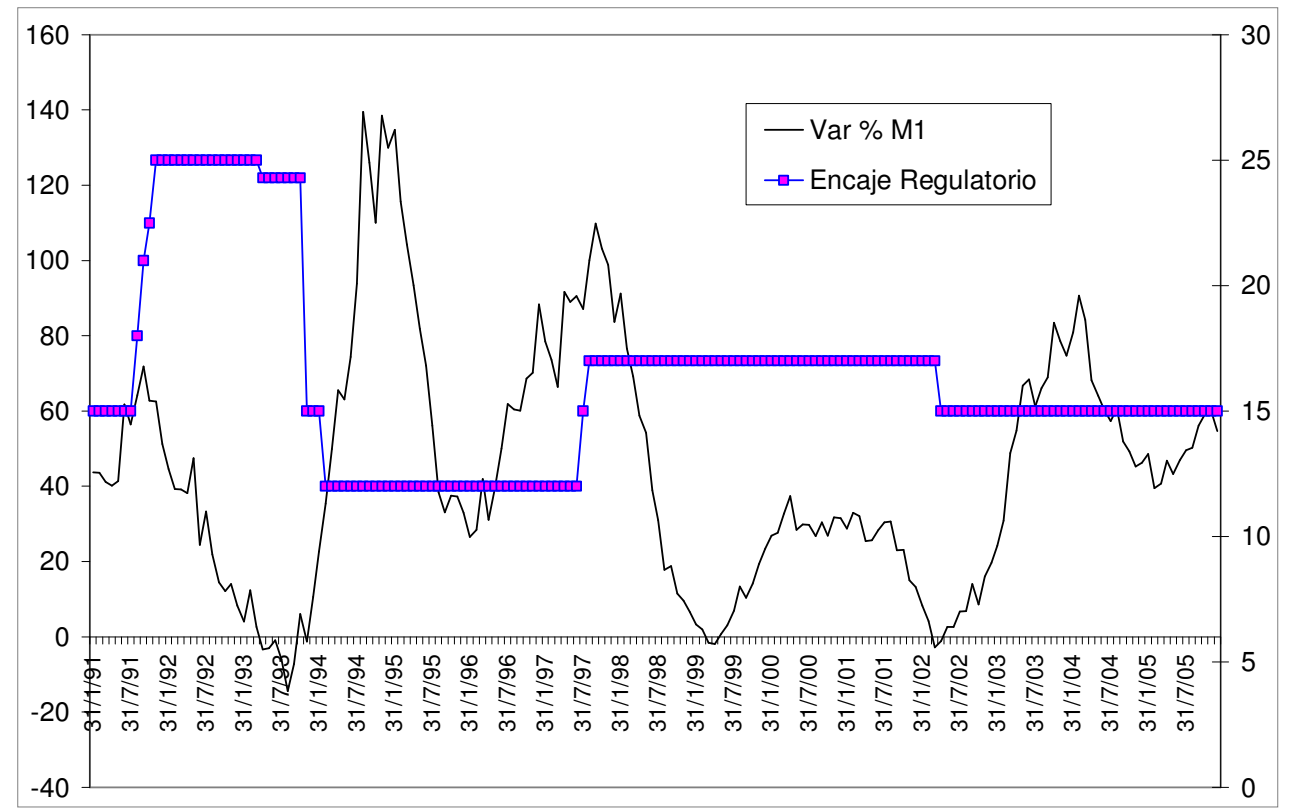

Claro está, aun habría que decir alguna palabra sobre la demanda y sobre la posibilidad de que estos ciclos monetarios expansivos hayan sido, o sigan siendo hoy, el producto de expansiones en la demanda de dinero. La demanda de dinero es usualmente entendida como una demanda de saldos reales. Esto tiene especial sentido en economías sometidas a procesos prolongados de inflación. La evolución mensual de la razón M1 contra el IPC base 1997 y de M2 contra el mismo índice de precios puede verse en la Figura 4. Aunque esta no es fielmente una representación de la demanda de dinero del público, pues supone (no sin controversia) que el mercado monetario se ajusta en forma rápida, y que la oferta y la demanda real de dinero se mantendrían en equilibrio, en cualquier caso, la figura parece indicarnos que la demanda saldos reales ha caído tendencialmente durante todo el lapso comprendido entre 1990 y 2002, con una visible recuperación sólo a partir de 2003. En otras palabras, sólo la última de las fases expansivas que hemos identificado en los agregados monetarios califica para ser 
considerada como 'promovida por la demanda' (demand-driven). No faltarían elementos analíticos para sostener esta hipótesis considerando que la economía venezolana ha crecido muy vigorosamente durante los últimos 9 trimestres, que las tasas de interés han mostrado un perfil a la baja en una forma ininterrumpida desde el año 2002, y que la implementación, a partir de febrero de 2003, del régimen administrado de divisas ha hecho irrelevante el arbitraje así como cualquier cálculo de riesgo cambiario, limitando también las elecciones de portafolio de los residentes domésticos a los instrumentos financieros domésticos denominados en moneda nacional.

Figura 4

Evolución de los saldos reales, 1990: 1-2005: 10

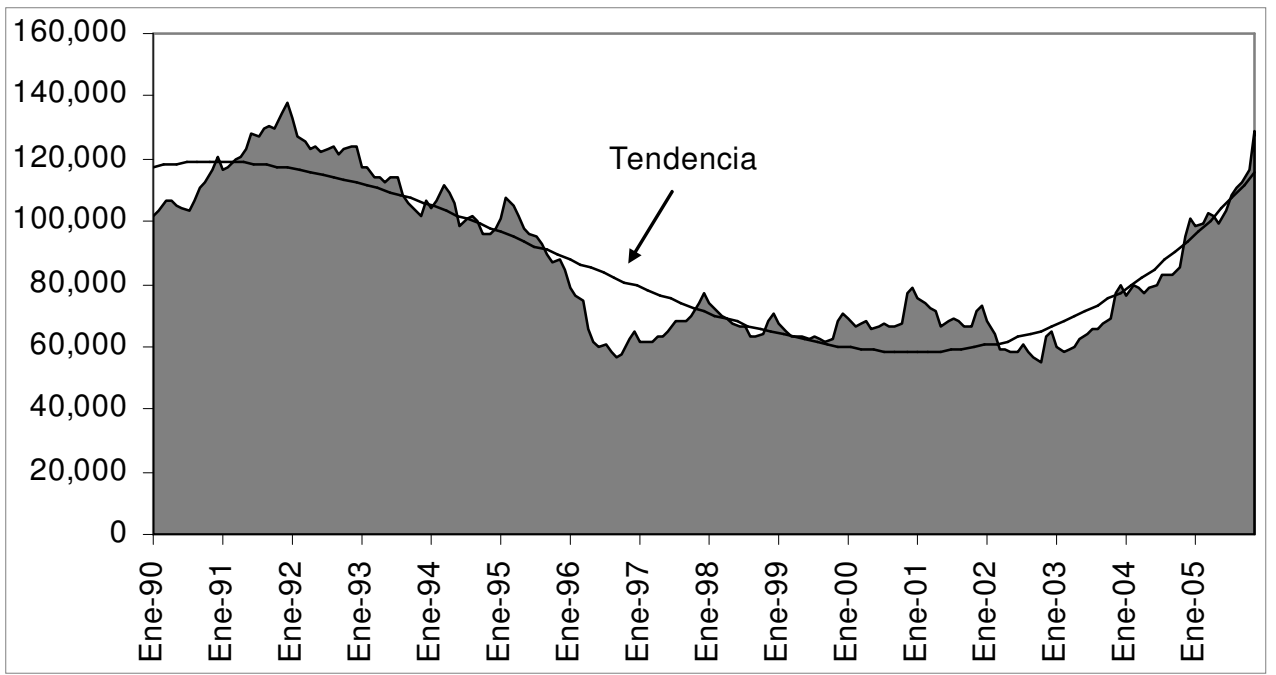

Fuente: Datos del BCV e Cálculos propios.

En resumen y hasta este punto, nuestra idea fundamental consiste en señalar que, a lo largo del período que va de 1990 a 2005, la evolución de los agregados monetarios manifiestan oscilaciones que son el resultado de episodios o choques que van más allá del control de la autoridad monetaria, y que las actuaciones del Banco Central, en lo que se refiere al control de los agregados monetarios como meta intermedia, no parecen ser exitosas.

\section{2 ¿Por qué el Banco Central pudiera no controlar los agregados monetarios?}

El Banco Central puede ejercer una influencia o un control más o menos razonable sobre la base monetaria, específicamente, cuando hace algún uso de la operaciones de mercado abierto, por ejemplo, a fin de esterilizar cambios en la base provenientes de otras fuentes, como los préstamos de ventanilla o las operaciones cambiarias de bolívares por dólar que inciden en la circulación 
monetaria. Pero el Banco Central no puede ejercer un control absoluto o completo del dinero base. ${ }^{5}$ Veamos algunas razones fundamentales que consideramos importante resaltar.

\subsection{Endogenidad promovida por el crédito}

La teoría del dinero-crédito señala que en la medida que los prestatarios son acreditados por el monto o por una parte del monto del préstamo en una cuenta dentro del sistema financiero, los préstamos bancarios constituyen una fuente de creación de depósitos. Un mayor volumen de depósitos se traduce automáticamente en mayores requerimientos de reservas o de activos líquidos. Esto será siempre así, si la razón de reservas obligatorias (o encaje legal) no ha variado, o si los bancos se ven obligados a liquidar depósitos. Si el sistema no tiene los recursos suficientes para atender el incremento requerido de las reservas, el Banco Central pudiera validar la expansión requerida de reservas haciendo uso de sus facilidades intentando evitar de esa manera una crisis de liquidez. Eventualmente, si el Banco Central no está dispuesto a hacer uso de sus facilidades, podría disminuir el encaje legal, lo cual es ya de por sí es una señal de expansión del dinero bancario por la vía de un incremento en el multiplicador monetario. De esta forma, cambios en los argumentos de la función de demanda de crédito hacen que la oferta de dinero-crédito varíe pro-cíclicamente con cambios en la demanda de crédito a través de un proceso de alteraciones sucesivas en el nivel de depósitos, de reservas y de la cantidad de dinero. ${ }^{6}$ En estas circunstancias la causalidad convencionalmente establecida es revertida. Las reservas bancarias no son el mecanismo que expande la oferta monetaria, sino más bien el déficit de gasto de las unidades deudoras reales incide en la demanda de crédito y es el crédito el que determina la cantidad de dinero.

\subsection{Preferencia por la liquidez del sistema financiero}

Parte de lo que se considera regularmente como el monto de dinero base o dinero de 'alto poder' de una economía está compuesto por las reservas que los bancos mantienen en poder del Banco Central. En esencia, estos recursos constituyen una obligación del Banco Central y un activo del resto de los bancos. Una porción relativamente importante de estas reservas las constituyen las llamadas reservas excedentes. En muchas circunstancias éstas se acumulan de

(5) Un compendio muy completo de las distintas formas de endogenidad del dinero apuntada en la literatura económica puede ser encontrada en Palley (2002).

(6) Esta es en esencia la posición de numerosos autores que han postulado la "endogenidad" del dinero como una propiedad atada al funcionamiento de los sistemas financieros modernos. No es el objeto de este breve estudio resumir o analizar la literatura al respecto, pero emblemáticos en este sentido han sido los trabajos de Kaldor (1970, 1982), Moore (1988, 1989) en los años setenta y ochenta, y Goodhart (1994), Palley (1994) y Wray (1992) en los noventa. 
acuerdo a decisiones voluntarias de cartera de los bancos en búsqueda de posiciones defensivas ante riesgos de liquidez, aunque también atienden a cambios en los rendimientos de otros activos en el portafolio de las instituciones. ${ }^{7}$

Supongamos, por ejemplo, que el Banco Central desea contraer la cantidad de dinero base y que para tal efecto realiza operaciones de venta de títulos con acuerdo de recompra (REPO). ${ }^{8}$ Los bancos compran los títulos con sus reservas disminuyendo en principio la cantidad de dinero, pero bien pudieran liquidar otras posiciones a fin de restituir sus posiciones líquidas al nivel "óptimo". En ese caso, la preferencia por la liquidez de los bancos hace que la cantidad de dinero base no necesariamente se modifique en la dirección o magnitud esperada por la autoridad monetaria. Sin embargo, mantener niveles óptimos de reserva constituye una dificultad en Venezuela y como veremos estos saldos líquidos se ven altamente impactados por otros movimientos macroeconómicos.

\subsection{Endogenidad de origen fiscal}

En una economía como la venezolana, en la cual el ciclo de los ingresos petroleros externo gobierna el comportamiento de los agregados macroeconómicos, y especialmente aquellos de naturaleza fiscal, la labor del Banco Central tiende a ser reactiva. No obstante, un largo trecho puede mediar entre la reacción deseada de las autoridades monetarias y las presiones a las que están sujetas sus decisiones. Incluso en períodos en donde los ingresos fiscales de origen petrolero crecen, el gasto público pudiera crecer en una proporción aún mayor y las cuentas públicas pudieran mostrar una brecha deficitaria.

Una situación deficitaria en las cuentas públicas hace que la tesorería emita bonos para conseguir dinero con qué pagar las cuentas del gobierno. Aunque los compradores potenciales de estos bonos pueden ser muy diversos, en muchas economías, y durante ciertos períodos históricos, el Banco Central ha resultado ser el comprador más importante de bonos públicos e incluso ha llegado a ser el prestamista más automático. Si los pagos, así como las emisiones, son poco predecibles, y si el Banco Central carece de autonomía, no tiene elección y se ve forzado por el gobierno a comprar directamente títulos públicos validando la expansión en una forma absolutamente desordenada. Ese no es propiamente el caso venezolano pues desde comienzos de la década de los noventas, el Banco

(7) En ocasiones se acumulan involuntariamente si la demanda de crédito o la oferta de otros activos sustitutos como los títulos del gobierno no es suficiente.

(8) Los REPO son operaciones de ventas de títulos con acuerdo de recomprarlos en el futuro, en fecha y condiciones financieras preestablecidas. Estas operaciones se efectúan en Venezuela desde el año 2001 y con títulos valores emitidos por el gobierno (como Bonos y Letras del Tesoro). En la práctica vinieron a sustituir a los llamados Títulos de Estabilización Monetaria (TEM) como instrumentos de absorción. 
Central ha sido liberado de la responsabilidad de financiar directamente déficit fiscales. De hecho, en la actualidad una norma constitucional, específicamente el Artículo 320 de la Constitución Nacional establece que "... En el ejercicio de sus funciones, el Banco Central de Venezuela no estará subordinado a directivas del Poder Ejecutivo y no podrá convalidar o financiar políticas fiscales deficitarias...". Esta disposición constitucional es ratificada por el artículo 36 de la Ley del BCV aprobada en el año 2001, pero ya existía una disposición muy parecida en la Ley que se remonta al año 1992. Sin embargo, aunque el Banco Central de Venezuela no compra directamente títulos públicos, en la práctica, actúa puntualmente comprando valores públicos mediante operaciones de mercado abierto. En este caso, el Banco Central está monetizando deuda de origen fiscal aunque de una forma indirecta. Igualmente, hay quienes consideran que la transferencia de utilidades de origen cambiario u operacional por parte del Banco Central al Gobierno Central son, en esencia, operaciones por debajo de la línea y que constituyen como tal financiamiento monetario del déficit. ${ }^{9}$

Al final del día el mayor problema que encuentran los analistas con este tipo de operaciones de monetización de deuda fiscal es que el control que pueda tener la autoridad monetaria sobre los agregados puede verse muy menoscabado si tiene que enfrentar en forma continua poderosas fuerzas o presiones políticas para extender financiamiento al sector público. Goldman and Sachs (2005) ha llamado recientemente la atención sobre este punto señalando que en el caso venezolano "la abrumadora dominancia fiscal erosiona la efectividad de la política monetaria" (p. 5).

\subsection{Variaciones no anticipadas en el multiplicador monetario.}

Para comprender por que el stock de dinero suele ser un múltiplo o una proporción mayor del dinero de alto poder expansivo, la teoría monetaria ha adoptado el concepto del multiplicador monetario. ${ }^{10}$ Convencionalmente se supone que el proceso de creación de dinero dentro del sistema bancario, y la elección que hace el público entre los instrumentos financieros generan un nexo entre la base monetaria y otros agregados monetarios más amplios. Conociendo el valor del multiplicador monetario, el control que el Banco Central puede ejercer sobre la base monetaria puede transmitirse en una forma más o menos predecible al

(9) Es preciso recordar, que en Octubre de 2002 la Asamblea Nacional en Venezuela resolvió modificar el artículo 71 de la Ley del Banco Central autorizando el traspaso de las utilidades netas semestrales desde el Banco Central hacia la Tesorería. El Banco Interamericano de Desarrollo, en un informe sobre la situación económica y perspectivas de la economía venezolana señalaba críticamente en su momento: "Es dudoso que este tipo de aumento en el patrimonio pueda calificarse como utilidad, pero si ese fuera el caso, dichas utilidades no deberían distribuirse" (BID 2002, p. 5).

(10) El modelo del multiplicador monetario fue originalmente desarrollado por Brunner (1961) y Brunner y Meltzer (1964). 
comportamiento de agregados monetarios más amplios como M1 o M2. Tal condición requiere que el nexo sea estable y sus cambios predecibles. ¿De que depende esta estabilidad o regularidad en los cambios del multiplicador monetario? James Tobin (1971) puso en entredicho, hace ya algunos años, esta supuesta estabilidad del multiplicador indicando que las decisiones discrecionales de cartera tanto de los bancos como del público gobiernan el curso que pueda tomar el multiplicador monetario, y estas decisiones pueden cambiar continuamente y en direcciones y magnitudes poco predecibles. ${ }^{11}$ El valor del multiplicador depende en definitiva de la razón reservas/depósitos y del coeficiente circulante depósitos. Pero ninguna de estos elementos está bajo el control directo de la autoridad monetaria. Por el contrario, el primero es parcialmente una variable de decisión discrecional de los bancos y depende del curso que tomen las tasas de interés de mercado de activos alternativos, de la tasa descuento y de la percepción de riesgo de liquidez que tenga el sistema financiero, en tanto que el segundo varía con las tasas de interés pasivas, con las tasas de interés relativas entre instrumentos, con el grado de confianza que tenga el público en el sistema de pagos y con la tasa de inflación esperada. ${ }^{12}$ La inestabilidad o endogeneidad es suficiente para explicar la inestabilidad del multiplicador. Si el multiplicador monetario no es estable o predecible, entonces el control de los agregados monetarios a partir de la cantidad de dinero base se dificulta en alto grado.

\subsection{Endogenidad de la base monetaria en una economía abierta con tipo de cambio fijo}

Una fuente adicional de perturbación de la base monetaria, pero aún más importante de considerar en el contexto de la economía venezolana, es la que proviene del arreglo cambiario y en particular del arreglo institucional que exhibe el Banco Central con el sector petrolero. Conviene recordar primero que la teoría económica indica que en una economía abierta con tipo de cambio fijo y libre movilidad de capital, la oferta de dinero termina siendo endógena ante choques de origen interno. El ejemplo típico señala que una expansión fiscal genera un alza temporal de tasas, provocando, en un contexto de alta sustitución de activos financieros, mayores entradas de capital y una situación temporal de exceso de oferta de divisas. El Banco Central reacciona con mayores adquisiciones de divisas para satisfacer la demanda por dinero local, lo que incrementa automáticamente la oferta de dinero base.

(11) Los bancos demandan liquidez en la forma de reservas excedentes y el público define la demanda de efectivo, depósitos a la vista, depósitos a plazo, etc.

(12) Darbha (2002) apunta que cambios en los rendimientos relativos, el riesgo, la tecnología de los mercados financieros, el ingreso y las preferencias de los agentes inciden directamente sobre estas decisiones de cartera. 
Sin embargo, en el caso de la economía venezolana el origen de los choques normalmente es externo y la movilidad de capital es una condición a menudo suspendida eventualmente por la recurrencia de las crisis externas, lo que hace que esta descripción sea algo diferente. ${ }^{13}$ La historia reciente en Venezuela suele comenzar con una mejoría sustantiva en los términos de intercambio (un choque favorable al país en los precios petroleros) que conmueve los ingresos en dólares del sector petrolero. La propiedad del recurso por parte del Estado obliga a la empresas de hidrocarburos a transferir parte de la "renta" al fisco, pero para hacer tal cosa, las regulaciones han dispuesto, desde hace muchos años, una regla según la cual los ingresos en dólares de las empresas deben ser adquiridos por el Banco Central. ${ }^{14}$ De esta manera, en cada operación de compra de dólares de origen petrolero la cuenta de reservas del BCV por el lado del activo se incrementa, por lo que el circulante por el lado de los pasivos debería hacerlo en la misma magnitud para mantener la consistencia contable. En la operación, la cantidad de dinero base ha aumentado sin que el Banco Central haya tomado decisión discrecional alguna.

Hay que decir, no obstante, que esta regla se ha venido condicionando. En primer lugar, el Banco Central ha llegado a un arreglo con la compañía estatal de petróleo, PDVSA, para no lanzar de inmediato los bolívares a la calle permitiéndole depositar el circulante en bolívares en una cuenta a cargo de la empresa petrolera y registrada en el pasivo del Banco. Sólo cuando PDVSA gira sobre este pasivo no monetario, se monetiza la operación de compra-venta de divisas y se hace efectivo el impacto sobre la base. Naturalmente, PDVSA puede recibir presiones del gobierno para incrementar su aporte fiscal en circunstancias de expansión del gasto público. En segundo lugar, una rápida y masiva acumulación de reservas internacionales por parte del Banco Central propició recientemente un cambio en la regla a partir del cual PDVSA sólo vende las divisas que se requieran para mantener un nivel "óptimo" de reservas. Desde Agosto de 2005 el excedente se ha venido depositando en un fondo en dólares administrado por el gobierno (el Fondo de Desarrollo Nacional, Fonden). Pero conviene decir que el manejo de este Fondo lo hace el Ejecutivo en una forma

(13) En los últimos veinte años el Banco Central y el Gobierno han suspendido la libre convertibilidad en tres ocasiones, implementando regimenes de control de cambio.

(14) Esta disposición gubernamental tiene su origen en agosto de 1944, cuando se promulgó el decreto $\mathrm{N}^{\circ} 178$, mediante el cual se estableció que las divisas originadas por las exportaciones de hidrocarburos y demás minerales combustibles, así como las provenientes de las diversas actividades de las Compañías Petroleras, seguirían siendo adquiridas de manera exclusiva por el Banco Central de Venezuela por cuenta del Gobierno Nacional. 
absolutamente discrecional, lo que le resta cualquier potencial restrictivo sobre el comportamiento de los agregados monetarios. ${ }^{15}$

\subsection{Inestabilidad en la demanda de dinero}

Un importante pre-requisito para el diseño y la implementación efectiva de un marco de política centrado en torno a metas monetarias cuantitativas lo constituye la existencia de una función de demanda de dinero estable y predecible. Se infiere, en consecuencia, que parte de las condiciones deseables que el Banco Central requiere para hacer un manejo preciso de los agregados monetarios son de naturaleza informacional. Tal pre-requisito es particularmente relevante para el establecimiento de metas monetarias que se propongan como objetivo el control de la inflación. Si la demanda de dinero no es predecible, las autoridades monetarias enfrentan el problema de no poder determinar con suficiente precisión si un aparente exceso de oferta monetaria refleja un cambio en los saldos monetarios deseados de los agentes o si las tenencias efectivas de dinero están temporalmente por encima del nivel que los agentes quisieran mantener en el largo plazo.

La evidencia empírica en muchas economías que han atravesado por procesos de liberalización financiera o donde los mercados financieros muestran un ritmo continuo de innovaciones, sugiere un grado de inestabilidad más o menos apreciable en la interacción entre el crecimiento del dinero, la actividad económica y la inflación. En ocasiones, cuando la función de demanda de dinero es exitosamente estimada u obtenida de manera forzada con la inclusión de variables ad-hoc, las predicciones que se generan fuera de la muestra son excesivamente volátiles. Por tanto, muchos analistas consideran que la demanda de dinero no puede ser considerada ya como una guía suficientemente segura para la formulación de la política monetaria.

\section{Ciertas evidencias para el caso venezolano}

Aunque los argumentos analíticos ayudan a hacerse un juicio bastante preliminar del problema sobre el control de los agregados monetarios, conviene dar un paso más allá y cotejar cada uno de ellos con alguna evidencia empírica así como con las experiencias que recogen otros estudios destinados a evaluar detalles sobre la política monetaria en Venezuela.

(15) Un informe emanado de Goldman Sachs (2005) en el mes de Diciembre sobre la economía venezolana concentra sus comentarios en los riesgos de una potencial expansión de la liquidez que eventualmente puede darse por la acumulación de estos saldos que escapan del control del Banco Central. 


\subsection{Dinero-Crédito: ¿Quién precede en esta relación?}

Con el objeto de verificar, en el caso venezolano, la hipótesis relativa a la endogenidad de la cantidad de dinero ante los desarrollos que ocurren en el mercado de crédito realizamos pruebas simples de causalidad estadística entre el crédito otorgado por los bancos y los agregados monetarios. Para ello usamos el horizonte más largo disponible para las series estadísticas mensuales a ser contrastadas que corresponde a cerca de 20 años de datos mensuales (desde enero de 1986 a Octubre de 2005). Las variables a ser contrastadas son el stock de crédito al sector privado, la cantidad de dinero M2, el stock M1 y la cantidad de dinero base. Previamente hemos verificado que, en logaritmo, todas estas variables son I(1), es decir, poseen una raíz unitaria y los resultados respectivos aplicando las pruebas KPSS se muestran en el Cuadro 2.

Cuadro 2

Prueba de raices unitarias

\begin{tabular}{|l|c|c|c|c|}
\hline \multicolumn{5}{|l|}{ Prueba KPSS } \\
\hline \multicolumn{1}{|c|}{ Vo: la serie es estacionaria } & $\begin{array}{c}\text { Ancho de } \\
\text { banda }\end{array}$ & Exógena & $\begin{array}{c}\text { Valor Critico } \\
\text { al 5\%* }\end{array}$ & $\begin{array}{c}\text { Estadístico } \\
\text { LM }\end{array}$ \\
\hline Log Base Monetaria & 12 & Constante & 0,463 & 1,923 \\
\hline Log Dinero M1 & 12 & Constante & 0,463 & 1,929 \\
\hline Log Dinero M2 & 12 & Constante & 0,463 & 1,928 \\
\hline Log Crédito & 11 & Constante & 0,463 & 2,074 \\
\hline$\Delta \log$ Base Monetaria & 2 & Constante & 0,463 & 0,060 \\
\hline$\Delta \log$ Dinero M1 & 3 & Constante & 0,463 & 0,145 \\
\hline$\Delta \log$ Dinero M2 & 1 & Constante & 0,463 & 0,118 \\
\hline$\Delta \log$ Crédito & 9 & Constante & 0,463 & 0,084 \\
\hline
\end{tabular}

* Valores críticos asintóticos de Kwiatkowski-Phillips-Schmidt-Shin (Tabla 1, 1992)

Los resultados provenientes de la pruebas de causalidad de Granger (que pueden observarse en el Cuadro 3) muestran sin ningún tipo de ambigüedad la precedencia estadística. La hipótesis nula de no-causación de los agregados hacia el crédito es rechazada por la prueba $\mathrm{F}$ en todos los casos, para los tres agregados (dinero base, oferta M1 y M2) y hasta con cuatro rezagos en cada de las regresiones que corresponden a las pruebas. De esta manera, el crédito no parece ser el "agente" promotor de cambios en los agregados monetarios, como propondría la teoría del dinero-crédito, y en consecuencia la búsqueda de las fuentes de creación de dinero hay que hacerla en otros lugares. 
Cuadro 3

Pruebas de causalidad de Granger

\begin{tabular}{|c|c|c|c|}
\hline \multicolumn{4}{|l|}{ Muestra: 1986: 1-2005: 10} \\
\hline Hipótesis Nula & Rezagos & Estadístico F & Probabilidad \\
\hline LogBM no causa LogCre & 1 & 4,488 & 0,035 \\
\hline LogBM no causa LogCre & 2 & 2,379 & 0,094 \\
\hline LogBM no causa $\log C r e$ & 3 & 6,227 & 0,000 \\
\hline LogBM no causa LogCre & 4 & 4,678 & 0,001 \\
\hline LogCre no causa $\log B M$ & 1 & 3,211 & 0,035 \\
\hline LogCre no causa LogBM & 2 & 1,214 & 0,298 \\
\hline LogCre no causa $\log B M$ & 3 & 1,203 & 0,309 \\
\hline LogCre no causa $\log B M$ & 4 & 2,224 & 0,067 \\
\hline LogM1 no causa LogCre & 1 & 16,992 & 0,000 \\
\hline LogM1 no causa LogCre & 2 & 7,181 & 0,000 \\
\hline LogM1 no causa LogCre & 3 & 10,888 & 0,000 \\
\hline LogM1 no causa LogCre & 4 & 8,220 & 0,000 \\
\hline LogCre no causa LogM1 & 1 & 0,506 & 0,477 \\
\hline LogCre no causa LogM1 & 2 & 0,051 & 0,949 \\
\hline LogCre no causa LogM1 & 3 & 0,704 & 0,550 \\
\hline LogCre no causa LogM1 & 4 & 0,703 & 0,590 \\
\hline LogM2 no causa LogCre & 1 & 11,122 & 0,000 \\
\hline $\log M 2$ no causa LogCre & 2 & 6,126 & 0,002 \\
\hline LogM2 no causa LogCre & 3 & 11,845 & 0,000 \\
\hline LogM2 no causa LogCre & 4 & 8,722 & 0,000 \\
\hline LogCre no causa $\log M 2$ & 1 & 2,965 & 0,086 \\
\hline LogCre no causa LogM2 & 2 & 0,547 & 0,578 \\
\hline LogCre no causa $\log M 2$ & 3 & 2,125 & 0,097 \\
\hline LogCre no causa LogM2 & 4 & 1,780 & 0,133 \\
\hline
\end{tabular}

Nota: BM: Base Monetaria y Cre: Stock de Crédito al Sector Privado

\section{2 ¿Qué determina el excedente de reservas bancarias?}

Considerando que existen algunos elementos para pensar que el excedente de reservas bancarias es una variable altamente condicionada por desarrollos que escapan del control del Banco Central, conviene observar entonces la evolución reciente de esta variable y tratar de establecer si este puede ser el caso venezolano. La Figura 5 muestra la evolución mensual de las reservas bancarias como proporción de los depósitos haciendo la distinción entre el nivel exigido regulatoriamente y el nivel voluntariamente mantenido en exceso por los bancos. 
Figura 5

Evolución del stock promedio mensual de reservas bancarias, 1995: 1-2005: 10

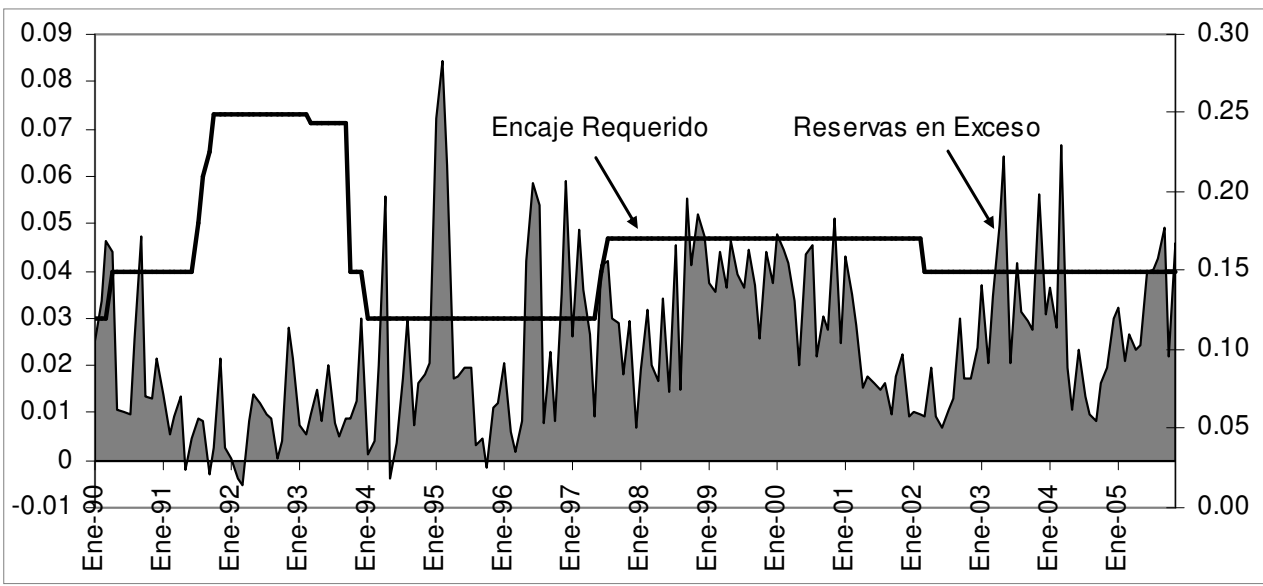

Fuente: Boletines Semanales de BCV.

Aunque no debe causar ninguna sorpresa la marcada inestabilidad relativa de la serie de reservas excedentes a depósitos con respecto a las reservas obligatorias, su elevada volatilidad en series mensuales abre algunas interrogantes. ${ }^{16}$ Así mismo, es preciso indicar que la volatilidad de la serie de reservas excedentes/depósitos a lo largo del periodo 1990: 1-2005: 11, es 1,7 veces mayor a la de la base monetaria. ${ }^{17}$ La pregunta lógica que emana en este sentido es la siguiente: ¿Corresponde esta sensible volatilidad de las reservas excedentes con una conducta activa del Banco Central cuyo propósito es mantener esta variable bajo control? Nuestra respuesta es negativa al respecto. Más allá de estas impresiones de tipo estadístico, existen algunos elementos de consideración adicionales que están íntimamente ligados a las características del mercado de reservas en Venezuela.

Los fondos mantenidos por encima del encaje no son otra cosa que el reflejo de decisiones estratégicas de las tesorerías de los bancos frente a la evolución de los pagos y los requerimientos de liquidez. Existe un mercado de saldos líquidos bancarios cuya demanda depende del nivel de transacciones vinculadas al funcionamiento del sistema pagos, pero también a factores precautivos asociados al grado de estabilidad de la economía. Vera y Zambrano (2001), por ejemplo, han destacado que uno de los aspectos que caracteriza al mercado de reservas en Venezuela es la poca fluidez de las operaciones de asistencia crediticia del BCV. Esto significa que el Banco Central no parece ser

(16) La volatilidad debería ser más bien una propiedad de series diarias o semanales. No así para series mensuales - si es que el Banco Central procura incidir en algún agregado monetario.

(17) Hemos usado la comparación de los coeficientes de variación en ambas series. 
quien ordinariamente y discrecionalmente regula la liquidez en este mercado. El Banco Central puede eventualmente cambiar el saldo de reservas, pero tiene poco control sobre otros eventos poco predecibles. A decir verdad, el mercado de reservas bancarias en Venezuela es más bien impactado por la evolución que toman las órdenes de pago de la tesorería nacional, y en otras ocasiones, de PDVSA. En general estos flujos suelen ser bastante erráticos, lo que hace que las tareas de coordinación sean complejas, especialmente si sobre estas agencias públicas privan objetivos en conflicto con los del Banco Central. En otras ocasiones, la irregularidad en los saldos líquidos en el mercado de reservas ha obedecido a movimientos o fuertes salidas no esperadas de capital. La Figura 5 deja ver, por ejemplo, que durante ciertos períodos (en estos últimos 15 años), los saldos líquidos o excedentes bancarios han caído. Esto es muy notable en los lapsos que van desde el año 1991 y hasta finales de 1993 y entre principios del año 2001 y mediados de 2002; es decir, justo en ocasiones en las cuales la economía estuvo sometida a fuertes salidas de capital (y a pérdidas de depósitos). El saldo promedio mantenido de reservas en exceso de los bancos en estas ocasiones estuvo por debajo del $1 \%$ (por debajo del promedio de $2,4 \%$ que ha mantenido desde 1990).

Una forma indirecta de corroborar la escasa regulación que ha tenido el BCV sobre el mercado de reservas, es constatando el patrón muy irregular que presenta la tasa de interés del mercado de fondos interbancario. Esta irregularidad se manifiesta incluso en series mensuales como la que muestra la Figura 6.

Figura 6

Tasa de interés interbancaria - Promedio mensual,

Oct. 1992 a nov. 2005

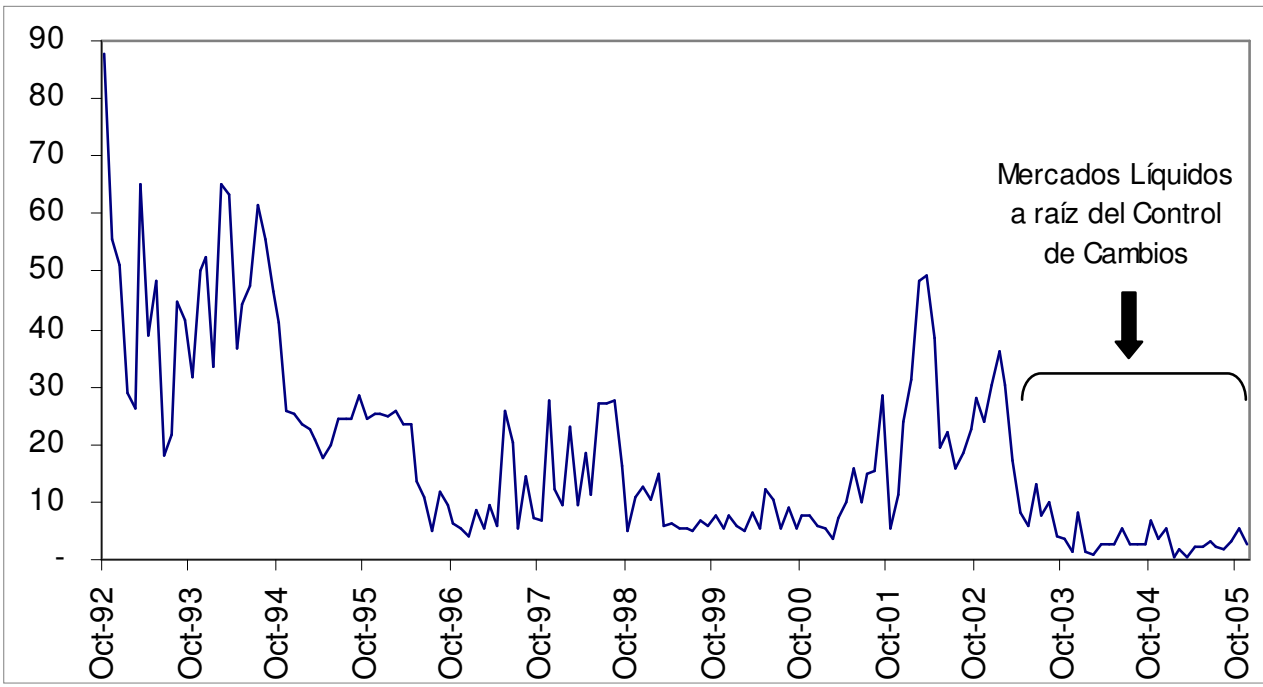

Fuente: Blomberg. 
Es sólo a partir del abrupto cambio en el régimen monetario y cambiario (que ocurre a partir de 2003) que se observan tasas bajas y más regulares con mercados muy líquidos. No obstante la regla en el período en estudio indica ondas dificultades para predecir la demanda de reservas, una escasa presencia del BCV en este mercado y la recurrencia de choques más allá del control de la autoridad monetaria.

Un analista escéptico estaría todavía dispuesto a señalar que dado los relativamente altos niveles de encaje legal que mantiene el Banco Central sobre el sistema financiero en Venezuela, el peso que pudiera tener la variabilidad de las reservas en exceso sobre las reservas bancarias totales no debería resultar inquietante. Al respecto hay que indicar que durante los últimos 15 años la relación promedio mensual de reservas excedentes a reservas requeridas ha sido de 16\%. Pero desde el inicio del control cambiario en Febrero de 2003 esta razón ha subido a $20 \%$, y desde Junio de 2005 se ha elevado a $26 \%$.

\section{3 ¿Incide la gestión fiscal sobre los agregados monetarios?}

La tesis del financiamiento monetario directo del déficit fiscal no parece calzar adecuadamente en el caso venezolano reciente y luce sólo útil para explicar quizás el breve interludio de la crisis financiera. ${ }^{18}$ Zambrano, Riutort y Páez (1995) confirman estas impresiones pero además señalan que, en el caso venezolano, ha sido más bien la devaluación del signo monetario la forma reciente de financiamiento del déficit, por lo que el gobierno no ha tenido que recurrir en forma importante a la monetización del déficit fiscal por la vía directa y tradicional. Sin embargo, las devaluaciones son eventos puntuales cuya asociación con las cuentas fiscales y monetarias sólo puede establecerse estadísticamente sobre la base de series de baja frecuencia (por ejemplo, anuales). Por otro lado, no todas las devaluaciones están asociadas a la necesidad de cubrir la brecha fiscal y más de un episodio ha estado ligado a la necesidad de solventar una crisis externa.

Siendo el caso de un país exportador de un recurso natural bajo propiedad pública, uno esperaría, como hemos argumentado anteriormente, que el patrón de los ingresos y del gasto público se vea altamente impactado por la evolución de los ingresos petroleros externos y que los agregados monetarios respondieran endógenamente a la evolución del gasto del gobierno. Así, la pro-ciclicidad del gasto público generaría inevitablemente efectos expansivos sobre la oferta monetaria, particularmente en momentos de incrementos significativos en los ingresos petroleros externos y aún incluso bajos los efectos de la esterilización que

(18) Hay que destacar al respecto que éste puede resultar ser un debate no cerrado. Algunos estudios hechos previos a la década de los noventas llegan a la conclusión que el déficit doméstico del sector público si tiene un impacto en la creación de base monetaria. Ver al respecto Diz (1988) y Vaez-Zadeh (1989). 
en un pasado generaban las salidas de capital y las acciones de política restrictiva que podía tomar el Banco Central.

A nuestro juicio, y para los efectos de las series mensuales que hemos venido estudiando, es más sencillo y más útil quizás buscar la relación que puede haber entre los ingresos petroleros externos, el gasto público y la base monetaria. La Figura 7 muestra, para series mensuales, el patrón que toman los ingresos petroleros externos y el gasto operacional del Gobierno Central en Venezuela para los últimos 15 años y hasta octubre de 2005. El coeficiente de correlación entre ambas variables toma un valor muy elevado $(94 \%){ }^{19}$ No obstante, esta comparación entre los valores nominales pierde atractivo informativo en una economía con inflación crónica y relativamente elevada como la venezolana. Alternativamente hemos tomado las series en términos reales, así como comparado los ingresos petroleros externos en bolívares reales con la tendencia del gasto operacional real (como se puede ver en la Figura 8). ${ }^{20}$ Las series muestran un patrón muy parecido entre sí y el coeficiente de correlación arroja un valor elevado y positivo $(0,69)$. Hemos hecho lo propio con las series mensuales normalizadas del gasto operacional del gobierno central y de la base monetaria para los últimos 15 años y hasta octubre de 2005. En las Figuras 9 y 10 se vuelve a revelar un patrón similar entre las series y el coeficiente de correlación es alto y positivo $(0,57)$. Resultados similares se encontraron para la relación entre el ingreso petrolero y la base monetaria (en términos nominales), aunque la correlación en los valores reales de estas variables no fue muy elevada (ver Figuras 11 y 12).

(19) Garcia, Rodríguez, Marcano, Penfold y Sanchez (1997) muestran, para series anuales, la asociación estrecha entre el gasto fiscal primario como porcentaje del PIB y los ingresos por exportación petrolera en primeras diferencias.

(20) La serie de gasto real reproduce muchas fluctuaciones y es por esa razón que hemos preferido trabajar con la tendencia. 
Figura 7

Evolución de los ingresos petroleros externos y del gasto operacional del Gobierno, 1990: 1-2005: 10

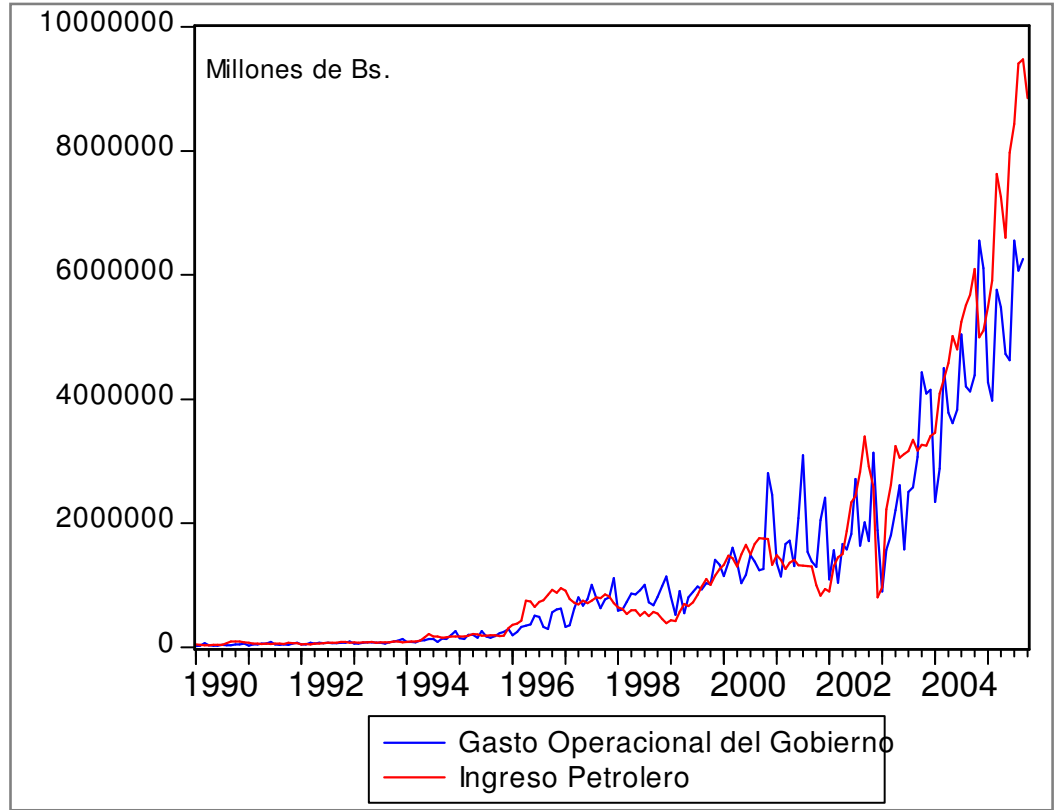

Fuente: Datos del BCV.

Figura 8

Ingreso petrolera real y tendencia del gasto operacional real 1990: 1-2005: 10

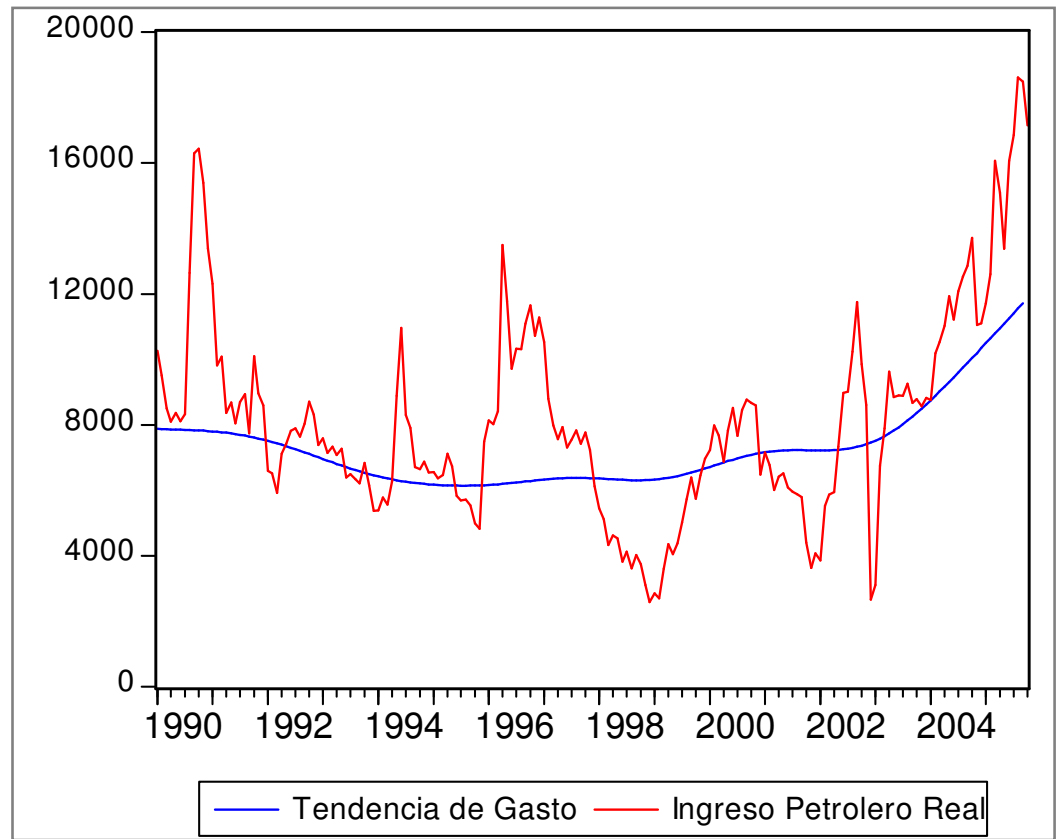

Fuente: Datos del BCV e Cálculos propios. 
Figura 9

Gasto operacional del Gobierno y base monetaria,

1990: 1-2005: 10

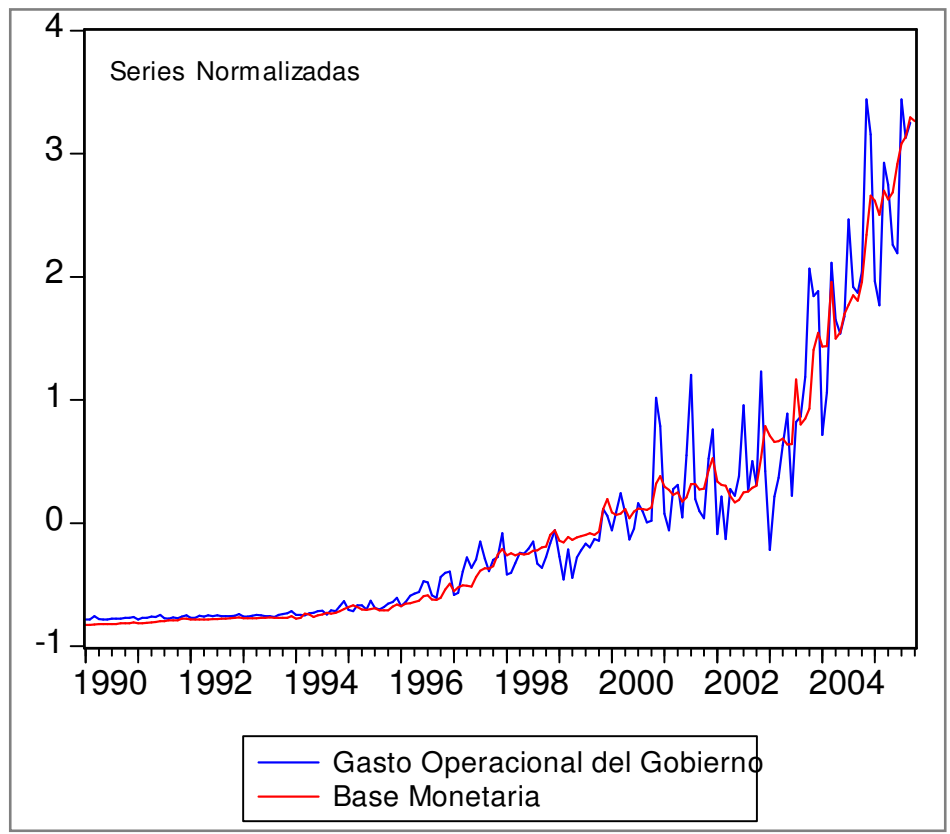

Fuente: Datos del BCV.

Figura 10

Tendencia del gasto operacional del Gobierno y base monetaria real, 1990: 1-2005: 10

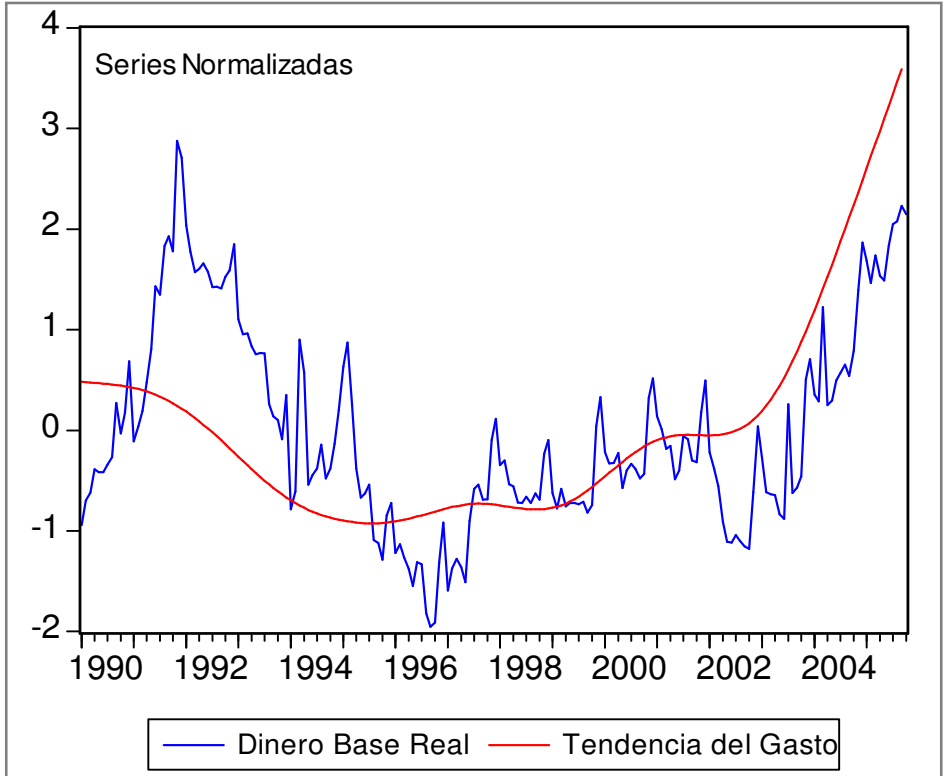

Fuente: Datos del BCV e Cálculos propios. 
Figura 11

Ingreso petrolero y base monetaria (enBs),

1990: 1-2005: 10

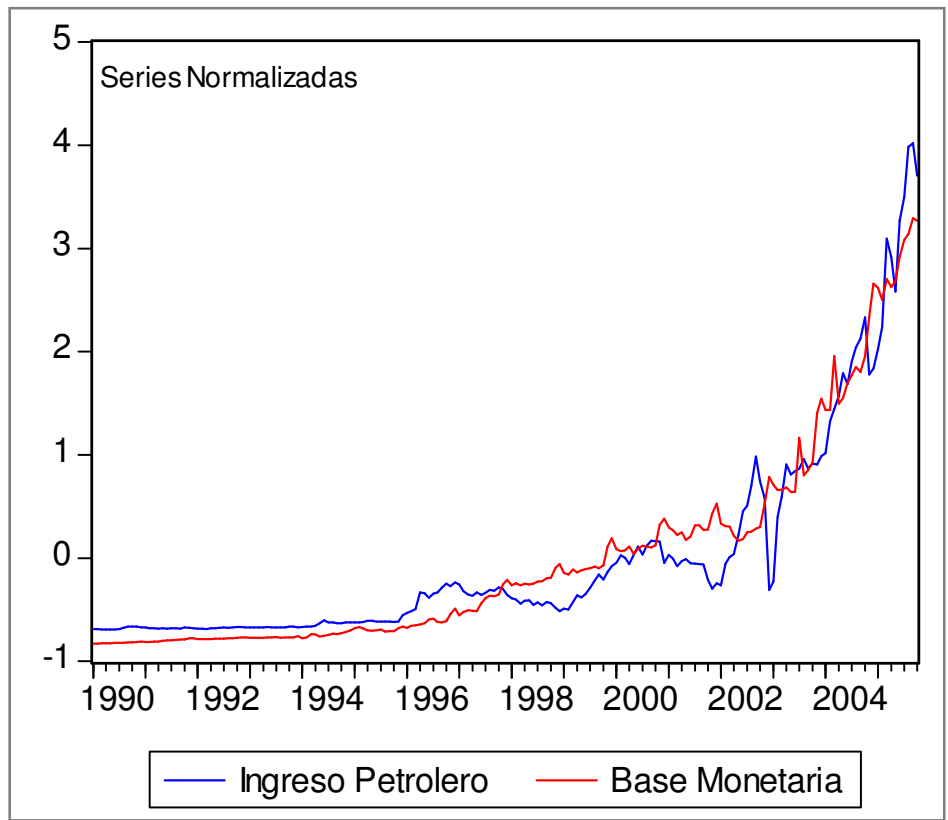

Fuente: Datos del BCV.

Figura 12

Ingreso petrolera real y base monetaria real,

1990: 1-2005: 10

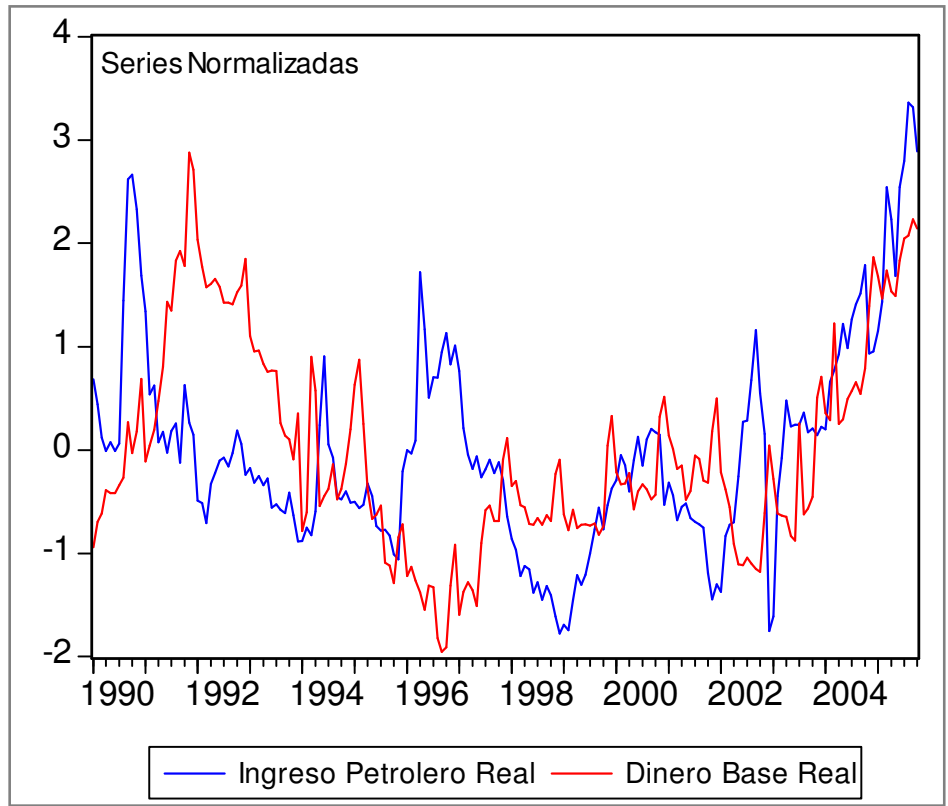

Fuente: Datos del BCV. 
Verificando el grado de estacionariedad de las series (en términos reales), determinamos que el ingreso petrolero real y la base monetaria en términos reales son I(1). ${ }^{21}$ Lo mismo no puede decirse del cálculo de la tendencia del gasto operacional del gobierno (ver Cuadro 4). Aplicamos la prueba de causalidad de Granger, primero entre el ingreso petrolero medido en bolívares reales y la base monetaria real, y luego, entre esta última variable y el valor tendencial del gasto del gobierno real. Los resultados pueden verse en el Cuadro 5 Las pruebas de causalidad corroboran la presunción de que el gasto fiscal incide en la evolución de la base monetaria pero a su vez es determinado por los ingresos petroleros externos. Estas, por supuesto, son malas noticias para un Banco Central que pretenda regular o ejercer alguna influencia sobre los agregados monetarios.

Cuadro 4

Prueba de raíces unitarias

\begin{tabular}{|c|c|c|c|c|}
\hline \multicolumn{5}{|l|}{ Prueba ADF } \\
\hline \multicolumn{5}{|c|}{ Ho: la serie tiene una raíz unitaria } \\
\hline Variable & Rezagos & Exógena & $\begin{array}{c}\text { Valor Critico } \\
\text { al 5\%* }\end{array}$ & Estadístico t \\
\hline Ingreso Petrolero Real & 0 & Constante & $-2,876$ & $-1,965$ \\
\hline Tendencia del Gasto Real & 5 & Constante & $-2,876$ & -0.246 \\
\hline Base Monetaria Real & 2 & Constante & $-2,876$ & $-1,273$ \\
\hline$\Delta$ Ingreso Petrolero Real & 0 & Constante & $-2,876$ & -12.052 \\
\hline$\Delta$ Tendencia del Gasto Real & 4 & Constante & $-2,876$ & 0,694 \\
\hline$\Delta$ Base Monetaria Real & 1 & Constante & $-2,876$ & -13.424 \\
\hline \multicolumn{5}{|l|}{ Prueba KPSS } \\
\hline \multicolumn{5}{|l|}{ Ho: la serie es estacionaria } \\
\hline Variable & $\begin{array}{c}\text { Ancho de } \\
\text { banda }\end{array}$ & Exógena & $\begin{array}{c}\text { Valor Critico } \\
\text { al } 5 \% * *\end{array}$ & $\begin{array}{c}\text { Estadístico } \\
\text { LM }\end{array}$ \\
\hline Ingreso Petrolero Real & 10 & Constante & 0.463 & 0,294 \\
\hline Tendencia del Gasto Real & 10 & Constante & 0.463 & 0,711 \\
\hline Base Monetaria Real & 10 & Constante & 0.463 & 0,278 \\
\hline
\end{tabular}

* Valores p de MacKinnon (1996)

** Valores críticos asintóticos de Kwiatkowski-Phillips-Schmidt-Shin (Tabla 1, 1992).

(21) La hipótesis nula de una raíz unitaria no se rechaza en niveles, pero es rechazada en diferencias con la prueba $\mathrm{ADF}$. 
Cuadro 5

Pruebas de causalidad de Granger

\begin{tabular}{|l|c|c|c|}
\hline \multicolumn{1}{|c|}{ Muestra: 1986: 1-2005: 10 } & Rezagos & Estadístico F & Probabilidad \\
\hline IPR no causa Base Real & 1 & 7,216 & 0,007 \\
\hline IPR no causa Base Real & 2 & 3,831 & 0,023 \\
\hline IPR no causa Base Real & 3 & 3,114 & 0,027 \\
\hline Base Real no causa IPR & 1 & 0,723 & 0,395 \\
\hline Base Real no causa IPR & 2 & 0,974 & 0,379 \\
\hline Base Real no causa IPR & 3 & 1,242 & 0,295 \\
\hline TenGasto no causa Base Real & 1 & 11,994 & 0,000 \\
\hline TenGasto no causa Base Real & 2 & 9,022 & 0,000 \\
\hline TenGasto no causa Base Real & 3 & 6,157 & 0,000 \\
\hline Base Real no causa TenGasto & 1 & 119,1 & 0,000 \\
\hline Base Real no causa TenGasto & 2 & 1,491 & 0,227 \\
\hline Base Real no causa TenGasto & 3 & 1,945 & 0,123 \\
\hline
\end{tabular}

Nota: IPR: Ingreso Petrolero Real y

TenGasto: Tendencia del Gasto Operacional Real del Gobierno

\subsection{La estabilidad del multiplicador monetario}

Siendo que las reservas totales de los bancos constituyen por definición un componente importante del multiplicador, es plausible entonces que todo lo que tenemos que decir sobre el comportamiento de las reservas bancarias pueda ser extendido al comportamiento del multiplicador. En esencia la inestabilidad del multiplicador, (si este fuera el caso), es en algún grado un sub-producto de la inestabilidad de la demanda de reservas bancarias.

¿Qué revela una simple inspección de la serie del multiplicador monetario? El multiplicador de la liquidez, definido por el BCV como la razón entre M2 y la base monetaria, evoluciona con mucha variabilidad especialmente durante todo el período que precede al año 1997 (ver Figura 13). La irregularidad de la tasa de crecimiento mensual que vemos en la Figura 14 muestra además lo difícil que sería predecir su evolución a corto plazo a partir de estas series.

Aunque no le hemos reportado en el trabajo, hemos revisado el comportamiento de la preferencia del público por el efectivo, que es en esencia el segundo componente importante del multiplicador, encontrando mucho más estabilidad (que en la reservas bancarias) y una tendencia al alza casi lineal. Esta tendencia podría explicar la caída secular del multiplicador a lo largo de todo el período. La incógnita que queda en el aire se remite entonces a determinar los factores que explican el alza tendencial en la preferencia del público por el efectivo. 
Figura 13

Multiplicadro monetario, 1990: 1-2005: 10

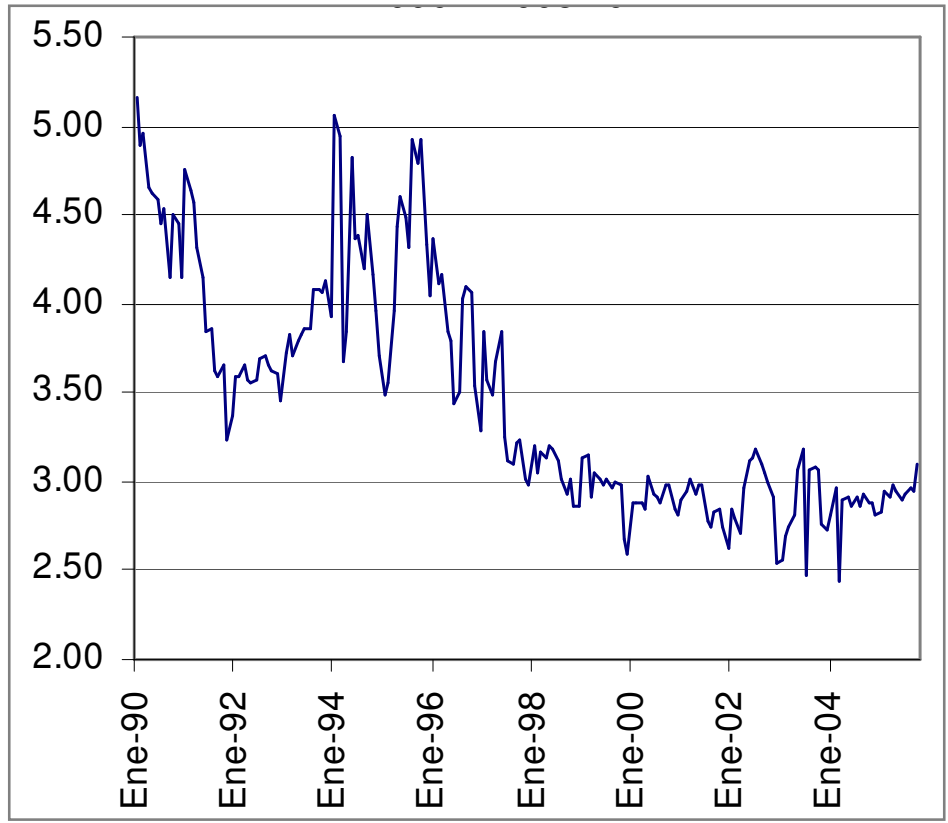

Fuente: Datos del BCV e Cálculos propios.

Figura 14

Variación \% intermensual del multiplicador, 1990: 1-2005: 10

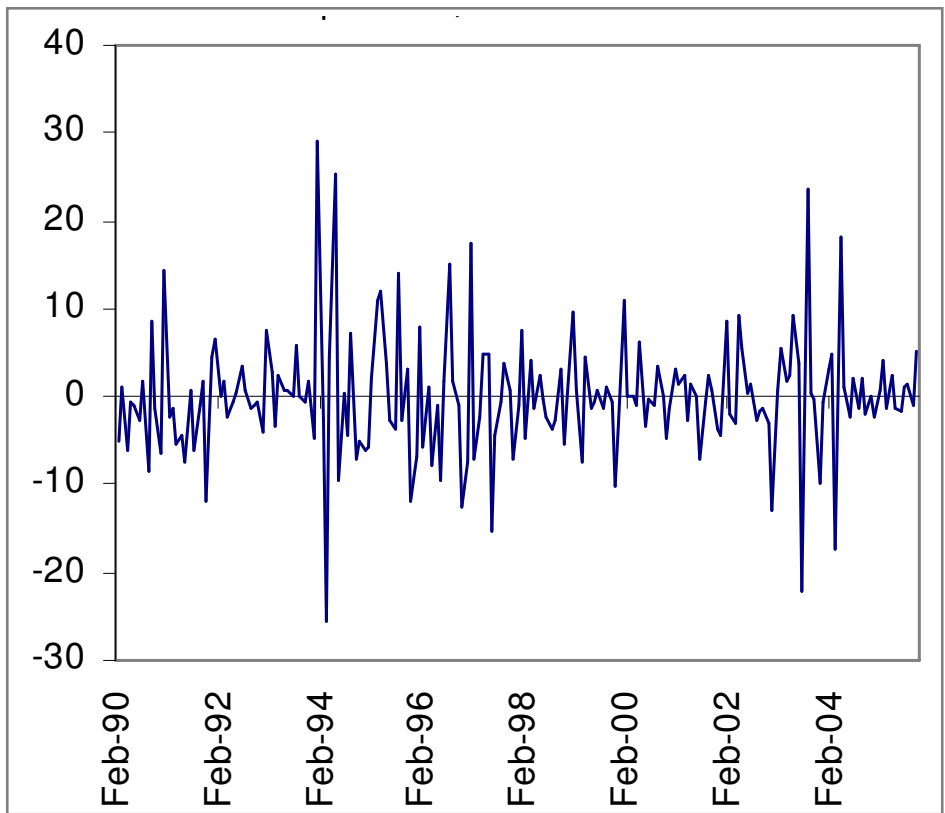

Fuente: Cálculos propios. 
La evidencia anterior es, sin embargo, insuficiente para establecer como un hecho cierto la inestabilidad del multiplicador monetario. Siguiendo a Ford y Morris (1996), Baghestani y Mott (1997) y Darbha (2002) es factible aplicar pruebas de cointegración a las series de base monetaria y el stock de dinero con el objeto de hacerse un juicio más apropiado sobre la estabilidad del multiplicador. La imposibilidad de rechazar la hipótesis nula de no-cointegración entre estas series implicaría la ausencia de una relación estable.

Para realizar la prueba de cointegración hemos expandido el horizonte de la series aglutinando el conjunto de datos para los últimos treinta años y con periodicidad mensual (entre enero de 1975 y noviembre de 2005). El análisis previo de las series correspondientes a la base monetaria y el stock de dinero M2 en logaritmos ya había indicado que estas son $\mathrm{I}(1){ }^{22}$ Hemos hecho las pruebas con las variables en niveles con resultados similares.

Dado que la relación es bivariada (base monetaria contra dinero), podemos considerar entonces una regresión para un modelo de dos variables I(1), $X_{1 t}$ y $X_{2 t}$, dada por

$$
X_{1 t}=\mu+\beta_{2} X_{2 t}+u_{t}
$$

El término, $u_{\mathrm{t}}$, se interpreta como la desviación de la relación anterior. $\mathrm{Si}$ $X_{1 t}$ y $X_{2 t}$ cointegran, entonces la desviación

$$
u_{t}=X_{1 t}-\mu-\beta_{2} X_{2 t}
$$

es un proceso estacionario con media igual a cero. De lo contrario choques sobre $X_{l t}$ y $X_{2 t}$ no tendrían efectos permanentes, las variables no co-varían y $u_{\mathrm{t}} \sim \mathrm{I}(0)$. Seguimos entonces la metodología de Engle y Granger (1987) procediendo a calcular los parámetros de una regresión en MCO entre estas dos variables, y luego, sobre la base de las propiedades globales del poder de la estimación, la prueba ADF se usa para verificar la hipótesis nula de que el error residual de la estimación es no estacionario. Como se desprende del Cuadro 6 la hipótesis nula sobre la no estacionariedad de los residuos no puede ser rechazada. Esto indica que la base monetaria y el stock de dinero M2 no forman un vector de cointegración. En consecuencia, la estabilidad del multiplicador no está garantizada.

(22) La prueba KPSS para ambas series indica, no obstante, que tampoco son estacionarias en diferencia. Pruebas adicionales indican que la estacionariedad se logra en segundas diferencias. 
Cuadro 6

Test de estacionariedad de los residuos

\begin{tabular}{|c|c|c|c|}
\hline \multirow[t]{2}{*}{ Variable } & \multicolumn{2}{|r|}{ Prueba ADF } & \multirow[b]{2}{*}{$-3,448$} \\
\hline & & Valor Crítico al 1\% & \\
\hline \multirow[t]{2}{*}{$\varepsilon_{\mathrm{t}}$} & $-1,975$ & Valor Crítico al 5\% & $-2,869$ \\
\hline & & Valor Crítico al $10 \%$ & $-2,571$ \\
\hline
\end{tabular}

* Valores p de MacKinnon (1996).

\subsection{La endogenidad del dinero base a los choques externos}

En la economía venezolana la estrategia para verificar la incidencia que tienen los choques externos de origen petrolero sobre la base monetaria podría comenzar buscando el grado de asociación que existe entre los movimientos en el ingreso petrolero externo petrolero y las reservas internacionales y entre las reservas y el dinero base. Dado que la serie de reservas internacionales mensual sólo está disponible desde 1996, recortamos eventualmente la muestra que hemos venido utilizando. En las Figuras 15 y 16 presentamos justamente el comportamiento de estas variables. Conviene apuntar que el grado de correlación entre los ingresos petroleros externos y el nivel de reservas internacionales (medidos en bolívares) es de 97,2\% y entre las reservas internacionales y la base monetaria es de 97,3\%. El sentido común indicaría que co-movimientos tan estrechos no pueden sino reflejar la incidencia que tienen los movimientos del mercado petrolero sobre la acumulación de activos en poder del Banco Central y ulteriormente sobre el dinero de alto poder expansivo (lo contrario sería un sin sentido). Por otro lado, si el Banco Central tuviera alguna capacidad para neutralizar las acumulaciones no deseadas de saldos monetarios, la correlación sería otra. El Banco Central sencillamente se ve desbordado por el impacto que pueden tener los desarrollos externos sobre su hoja de balance. Curiosamente, un informe publicado recientemente por el FLAR (2003) hace referencia a este fenómeno, pero en un sentido episódico. El informe señala; "En términos de las fuentes de la base monetaria la tendencia expansiva se explica por el aumento de las reservas internacionales que se viene presentando bajo el control de cambios" (p. 10). Pero lo que es descrito como una situación puramente episódica, se trata en realidad de una condición estructural que afecta a la política monetaria. Hay que hacer notar que la proporción del acervo de reservas internacionales con respecto a la base monetaria ha sido históricamente muy alta en Venezuela, ${ }^{23}$ pero además ha venido creciendo desde los primeros meses del año 2002 con el choque petrolero positivo externo, y eventualmente con la introducción del régimen de control de cambios en 2003.

(23) Las reservas han sido, en promedio mensual para los últimos diez años, cerca de 2,8 veces el dinero base. 
Figura 15

Ingreso petrolero y reservas internacionales (bolívares), 1996: 1-2005: 10

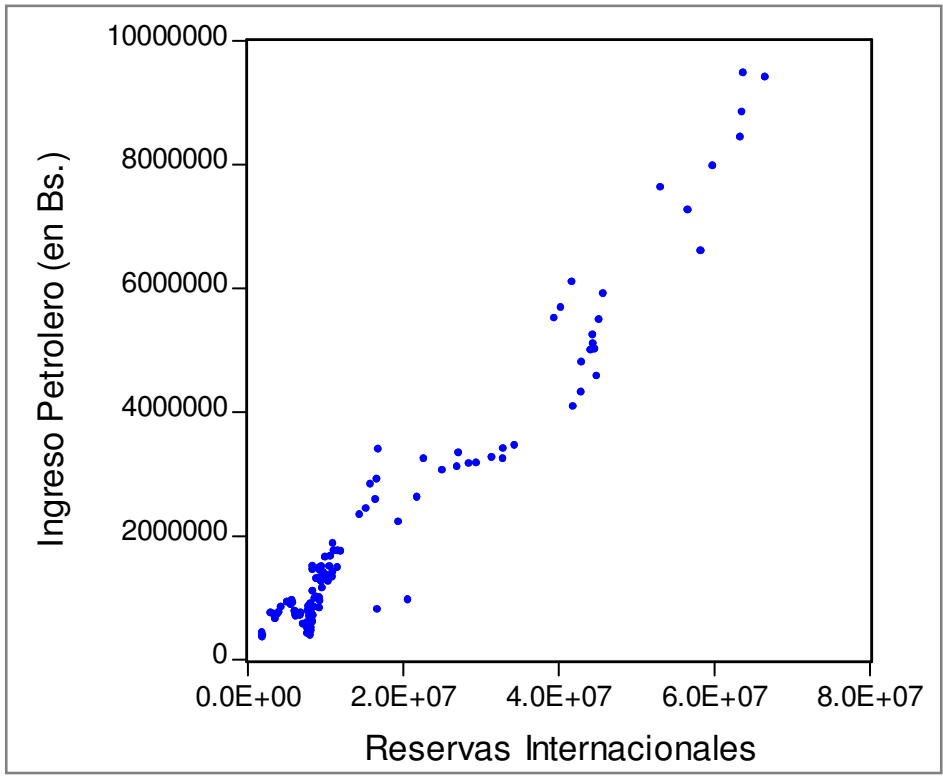

Figura 16

Reservas internacionales y base monetaria (bolívares), 1996: 1-2005: 10

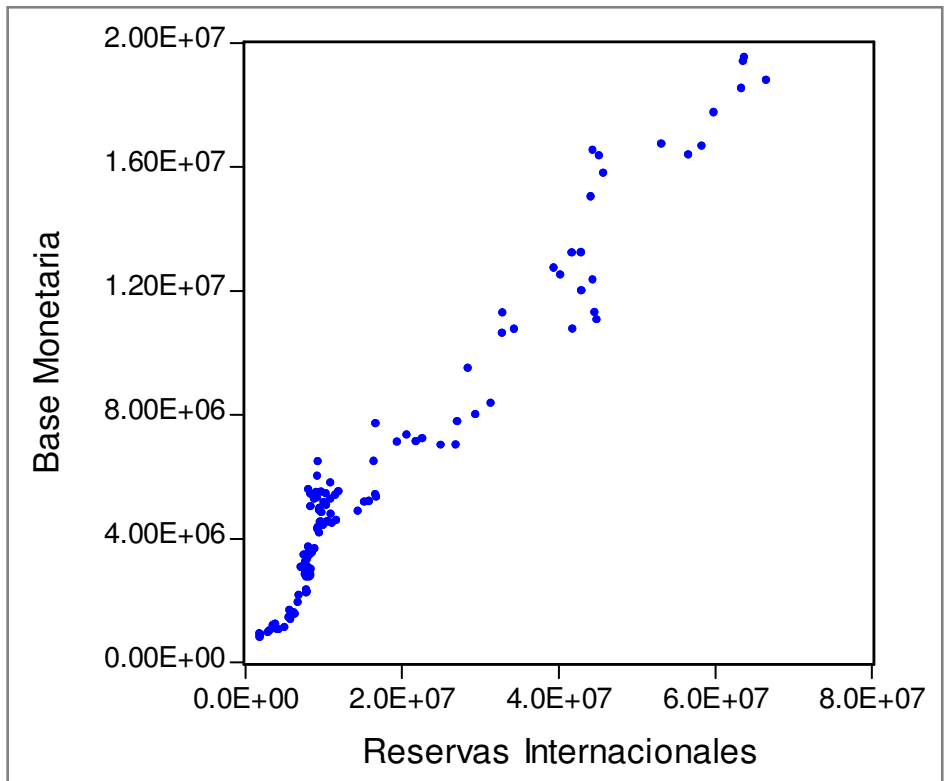

\section{6 ¿Qué puede decirse sobre la demanda de dinero a corto plazo?}

Concebir tan sólo la posibilidad de estimar una función de demanda de dinero estable en una economía que en los últimos 20 años ha sido sometida a una 
variedad de eventos pasando por programas de ajuste tipo shock, crisis financiera, volatilidad en el entorno político, salidas de capital, repentinos controles sobre la operaciones en divisas, múltiples devaluaciones y un variado menú de arreglos cambiarios, puede lucir atrevido. ${ }^{24}$ Sin embargo, estos atrevimientos abundan, especialmente en los últimos 10 años. El Cuadro 7 presenta un resumen de los trabajos empíricos más recientes hechos con el propósito de estimar una función de demanda de dinero para Venezuela.

Cuadro 7

Estimaciones de la función de demanda de dinero para Venezuela

\begin{tabular}{|c|c|c|c|c|}
\hline Estudio & $\begin{array}{c}\text { Variable } \\
\text { Dependiente }\end{array}$ & $\begin{array}{l}\text { Frecuencia y } \\
\text { Lapso de la } \\
\text { Data }\end{array}$ & $\begin{array}{c}\text { Técnica } \\
\text { Econométrica }\end{array}$ & Variables Explicativas \\
\hline $\begin{array}{l}\text { Sánchez } \\
\text { (1995) }\end{array}$ & M1 Real & \begin{tabular}{|c|} 
Trimestral \\
1980:1-1994:2
\end{tabular} & VAR & $\begin{array}{l}\text { PIB Real, Tasa Nominal } \\
\text { Pasiva a } 90 \text { días, Inflación }\end{array}$ \\
\hline Páez (1995) & M1 Real & $\begin{array}{c}\text { Trimestral } \\
\text { 1983:1-1992:4 }\end{array}$ & Cointegración & $\begin{array}{l}\text { PIB Real, Tasa Nominal } \\
\text { Pasiva, Dummy por } \\
\text { Innovación }\end{array}$ \\
\hline $\begin{array}{l}\text { Copelman } \\
\text { (1996) }\end{array}$ & M1 Real & $\begin{array}{c}\text { Trimestral } \\
\text { 1978:1-1991:4 }\end{array}$ & $\begin{array}{c}\text { Cointegración } \\
\text { y ECM }\end{array}$ & $\begin{array}{l}\text { PIB Real no petrolero, } \\
\text { Inflación, Dummy por } \\
\text { Innovación }\end{array}$ \\
\hline $\begin{array}{l}\text { Cartaya, Roo } \\
\text { y Sánchez } \\
\text { (1997) }\end{array}$ & M1 Real & $\begin{array}{c}\text { Mesual 1980:1- } \\
1996: 3\end{array}$ & $\begin{array}{l}\text { Cointegración } \\
\text { y ECM }\end{array}$ & $\begin{array}{l}\text { Valor Real Cheques en } \\
\text { Cámara de Compensación, } \\
\text { Inflación, Índice de } \\
\text { Variabilidad de los Precios, } \\
\text { Tasa de Interés Pasiva }\end{array}$ \\
\hline $\begin{array}{l}\text { Arreaza, } \\
\text { Fernandez y } \\
\text { Delgado } \\
(2000)\end{array}$ & M1 y M2 Real & \begin{tabular}{|c|} 
Trimestral \\
1984:1-1999:4 \\
y Mensual \\
$1989: 1-$ \\
$1999: 12$ \\
\end{tabular} & VAR y OLS & $\begin{array}{l}\text { PIB Real, Inflación, Tipo de } \\
\text { Cambio Nominal, Tasa de } \\
\text { Interés Pasiva a } 90 \text { días, Tasa } \\
\text { de CDs USA a } 90 \text { días }\end{array}$ \\
\hline $\begin{array}{l}\text { Ramajo } \\
(2001)\end{array}$ & M1 Real & $\begin{array}{c}\text { Trimestral } \\
\text { 1983:1-1994:4 }\end{array}$ & $\begin{array}{l}\text { Cointegración } \\
\text { y ECM }\end{array}$ & $\begin{array}{l}\text { PIB Real, Tasa de Interés } \\
\text { Nominal Pasiva a } 90 \text { días, } \\
\text { Inflación }\end{array}$ \\
\hline $\begin{array}{l}\text { Cuevas } \\
(2002)\end{array}$ & M1 y M2 Real & $\begin{array}{c}\text { Trimestral } \\
\text { 1993:1-2001:4 }\end{array}$ & VECM & $\begin{array}{l}\text { PIB Real, Inflación, Tipo de } \\
\text { Cambio Nominal, Tasa de } \\
\text { Interés Pasiva a } 90 \text { días, Tasa } \\
\text { de CDs USA a } 90 \text { días }\end{array}$ \\
\hline $\begin{array}{l}\text { Bjorland } \\
(2003)\end{array}$ & M2 Real & $\begin{array}{c}\text { Trimestral } \\
\text { 1985:1-1999:1 }\end{array}$ & $\begin{array}{l}\text { Cointegración } \\
\text { y ECM }\end{array}$ & $\begin{array}{l}\text { PIB Real, Tasa de Interés } \\
\text { Nominal Paiva a } 90 \text { días, Tipo } \\
\text { de Cambio }\end{array}$ \\
\hline
\end{tabular}

(24) Un esfuerzo por sintetizar los principales eventos macroeconómicos de la economía venezolana, desde finales de los años ochenta, comenzaría por destacar la devaluación del bolívar ocurrida en febrero de 1989, el programa de ajuste macroeconómico ortodoxo que le siguió, el intento de liberalización financiera iniciado en los años noventa, la crisis financiera y externa que estallan en el año 1994, el control de cambio ocurrido a raíz de estas crisis, la eliminación del control de cambio y la implementación del régimen de banda cambiaria a mediados de 1996, la caída estrepitosa de los precios del petróleo en 1998, el estallido de la crisis cambiaria del año 2002 con la implementación de un régimen transitorio de flexibilidad, el nuevo choque al alza en los precios del petróleo y la implementación de un nuevo control de cambios en febrero de 2003. 
Curiosamente, la mayor parte de los estudios se concentran en la estimación del agregado M1 real para series de frecuencia trimestral. Las estimaciones de M2 real son, cuando menos, problemáticas y sólo el trabajo de Bjorland (2003) encuentra una relación estable. Para serie mensuales, como las que hemos venido analizando en este estudio, la evidencia es mixta. Cartaya, Roo y Sánchez (1997) encuentran una relación congruente y estable para la demanda de M1 en términos reales, pero un estudio más reciente de Arreaza, Fernández y Delgado (2000) no encuentra relaciones robustas con data mensual. Esta ambigüedad en los resultados con data mensual justifica parcialmente las afirmaciones de Guerra, Pagliacci y Zavarce (2002, p. 8) cuando señalan que "no hay evidencia robusta sobre la demanda de dinero con data mensual para los agregados M1 y M2, lo cual dificulta la operacionalización de un corredor de dinero base o cualquier otro agregado más amplio". Por otra parte, los estudios que estiman exitosamente una función de demanda de dinero con data trimestral, cuando no requieren relajar la hipótesis de coeficientes constantes como en Ramajo (2001), necesitan, como en Páez (1995) y Copelman (1996), de la introducción de variables dicotómicas que recojan (a decir de los autores) las innovaciones en los mercados financieros. Sin estos arreglos la inestabilidad es la norma. Así mismo, prevalece en todos estos ejercicios una alta sensibilidad de las elasticidades de largo plazo al enfoque usado en la estimación, a la especificación elegida y a la selección de la variable que representa el costo de oportunidad del dinero. Por último, los resultados afirmativos de las pruebas de cointegración que se reportan en la mayoría de estos estudios deben ser tomados con cautela pues se remiten a series cuyo horizonte temporal, en el mejor de los casos, no van más allá de 16 años. Este aspecto expone a la mayoría de los ejercicios a la crítica de Hakkio and Rush (1991) quienes argumentan que la cointegración es una propiedad de largo plazo y que de por sí requiere de horizontes temporales largos a fin de ser probada con rigor.

\section{4 ¿Qué es entonces lo que el Banco Central controla?}

La respuesta no es nada clara, pero bien vale aclarar que desde el levantamiento de los controles (a los que estuvo sometida la economía venezolana e la década de los años ochenta) y la introducción de programa de ajuste ortodoxo en 1989, la gestión de la política monetaria tampoco presenta un patrón absolutamente regular. La estrategia - sino el proceso mediante el cual se lleva a cabo la política monetaria - ha pasado por al menos cinco distintas fases. Dorta y Guerra (2003, p. 3) señalan que a partir de 1989 "la política monetaria aplicada por el BCV tenía como objetivo específico regular los excesos de liquidez con el propósito de moderar las presiones sobre los precios y el tipo de cambio". Mirabal (1999) coincide con estas impresiones y describe el período que va entre 1989 y 1992 como uno en el cual se utilizó un programa monetario donde el dinero base 
fungió como objetivo intermedio en un ambiente de liberalización en el tipo de cambio y las tasas de interés. Durante los años 1992 y 1993, la actuación del Banco Central se vio seriamente influenciada por factores asociados al clima de inestabilidad política que se posaba sobre el gobierno de Carlos Andrés Pérez. En este ambiente, la preferencia por un tipo de cambio más rígido - comentada en Mirabal (1999) - a partir de la cual el BCV propiciaba el ajuste entre la oferta y la demanda de dinero mediante variaciones en las reservas internacionales, llevó a una acción más activa donde el Banco Central no sólo usaba subastas semanales de bonos cero cupón para restringir la liquidez, sino además colocaba directamente certificados de depósitos para captar recursos de la banca y aliviar la presión sobre el mercado cambiario. Para finales de 1993 el clima de desconfianza y las salidas de capital generaron una gran estrechez de liquidez lo que condujo al Banco Central a darle un giro completo a su política. El Banco Central atendió las necesidades de liquidez de los bancos con operaciones poco comunes como los anticipos a muy corto plazo y bajando el encaje regulatorio de 25 a 15 por ciento. Desde el año 1994, cuando estalla la crisis financiera, y hasta el año 1995, el BCV abandonó completamente su política de control de los agregados y se convirtió en un proveedor de liquidez de última instancia en un contexto en donde incluso la demanda de dinero venía cayendo aceleradamente. Un régimen de control de cambio se implementa en 1994 para dar paso a mediados de 1996 a un régimen de banda cambiaria. Según Dorta y Guerra (2003, p. 5) el Banco Cental siguió entonces "un programa financiero basado en el control de los activos internos netos como variable instrumental". Arreaza, Ayala y Fernandez (2001, p. 26) apuntan que durante el año 1997 la política buscaba una vez más "procurar que los agregados monetarios evolucionaran de forma consistente con la demanda de dinero". Una crisis de grandes dimensiones comenzó a gestarse en los primeros meses del año 2001 dos años después de que el Presidente Hugo Chávez se relegitimara en el curso de unas elecciones. La agudización de la conflictividad política con el sector privado y una parte de la sociedad civil, en un contexto inflacionario y de abierta sobrevaluación de la moneda, intensificaron las salidas de capital. Así, de un nivel relativamente cómodo de reservas internacionales de 16.600 millones de US\$ a finales de Enero de 2001, el BCV pasó a registrar 10.544 millones de US\$ a finales de Enero de 2002, lo que contabilizaba una pérdida de activos externos netos de $36 \%$ en sólo 12 meses. El 13 de febrero, ante la inminencia del colapso cambiario, el gobierno decidió abandonar el régimen de bandas, propició el ajuste cambiario y anunció la puesta en práctica de un sistema de flotación. El colapso del régimen de banda cambiaria producido en Febrero de 2002 obligó al BCV a diseñar en Abril de ese año una nueva estrategia que se denominó, para entonces, "estrategia monetaria flexible".

Las referencias en torno a la forma en que ha operado la estrategia monetaria flexible no son abundantes, y las descripciones conocidas tampoco son 
del todo claras. ${ }^{25}$ Dorta y Guerra (2003, p. 8), por ejemplo, indican, que la estrategia "estableció un corredor para la variable intermedia, dinero base, mientras que el BCV señalizaba el perfil de su política mediante la tasa de interés de corto plazo de las operaciones de repos". Pero Pagliacci y Ruda (2004, p. 3) señalan que: "en la estrategia monetaria flexible, las acciones de política se definen como los movimientos de las tasas de interés ofrecidas por el Banco Central en las operaciones de mercado abierto". A primera vista pareciera presentarse una ambigüedad en torno al objetivo intermedio de la estrategia. Sin embargo, Olivo (2003) explica que aunque un corredor para el dinero base funge como variable intermedia, la variable operativa para ajustar el dinero base al nivel deseado es la tasa de interés de corto plazo.

La estrategia monetaria flexible asume, por tanto, que la base monetaria está sujeta al control del Banco Central a través del manejo de la tasa de interés de corto plazo. En torno a la cuestión de como el comportamiento de las tasas incide en la evolución de la base monetaria, no existe evidencia empírica sólida para Venezuela como tampoco una explicación acabada de los mecanismos de transmisión. Es plausible suponer, que el BCV intenta conocer a priori la demanda de dinero e incidir parcialmente en ella con cambios provocados en la tasa de interés, para luego acomodar, según sea el valor del multiplicador monetario, la oferta de dinero base a un nivel consistente con el equilibrio en el mercado monetario. ${ }^{26}$ Pero no está de más recordar que la consecución de un programa monetario de esta naturaleza supone entonces conocer y predecir el comportamiento de la demanda de dinero (específicamente sus reacciones a cambios en las tasas), supone además un multiplicador estable y predecible, y adicionalmente un control férreo de la base monetaria. Ninguna de estas condiciones parece estar garantizada a decir de los argumentos y la evidencia antes presentada en este trabajo. Si algún control puede ejercer el Banco Central en esta secuencia de acciones, éste se da sólo sobre las tasas de interés y a través de las operaciones Repo de inyección o Repo y certificados de absorción. ${ }^{27}$ Los demás es estricta especulación. La Figura 17 muestra una panorámica del comportamiento

(25) Olivo (2003) señala que la estrategia monetaria flexible consiste en un esquema de transición propuesto por los técnicos del $\mathrm{BCV}$, que combina elementos del enfoque de agregados monetarios con el de metas de inflación.

(26) Olivo (2003, p. 60) parece sugerir este procedimiento cuando afirma que "la trayectoria central del corredor se construye con base en la ecuación cuantitativa expresada en términos de variaciones porcentuales".

(27) Hay que señalar adicionalmente que desde mayo de 2005 el control sobre las tasas es aún más ceñido pues el $\mathrm{BCV}$ puso en práctica un esquema de topes máximos y mínimos sobre las tasas de interés bancarias, atando estos topes a tasas referenciales marcadas por el instituto. El esquema llevó inicialmente la tasa activa máxima a $28 \%$ y la pasiva mínima para los depósitos de ahorro y a plazo a $6,5 \%$ y $10 \%$ respectivamente. En consecuencia, el BCV no sólo viene intentando ejercer un control indirecto de las tasas por medio de sus operaciones de mercado abierto, sino que además ha recurrido a un sistema de determinación administrada de las tasas bancarias similar al usado en un pasado. 
de las tasas bancarias en comparación con los rendimientos promedios mensuales obtenidos en las operaciones de mercado abierto, y cuan ceñidas han estado unas a otras desde que se inició la 'estrategia monetaria flexible’ en abril de 2002.

Figura 17

Evolución de las tasas bancarias y marcadora, 2002: 3-2005: 10

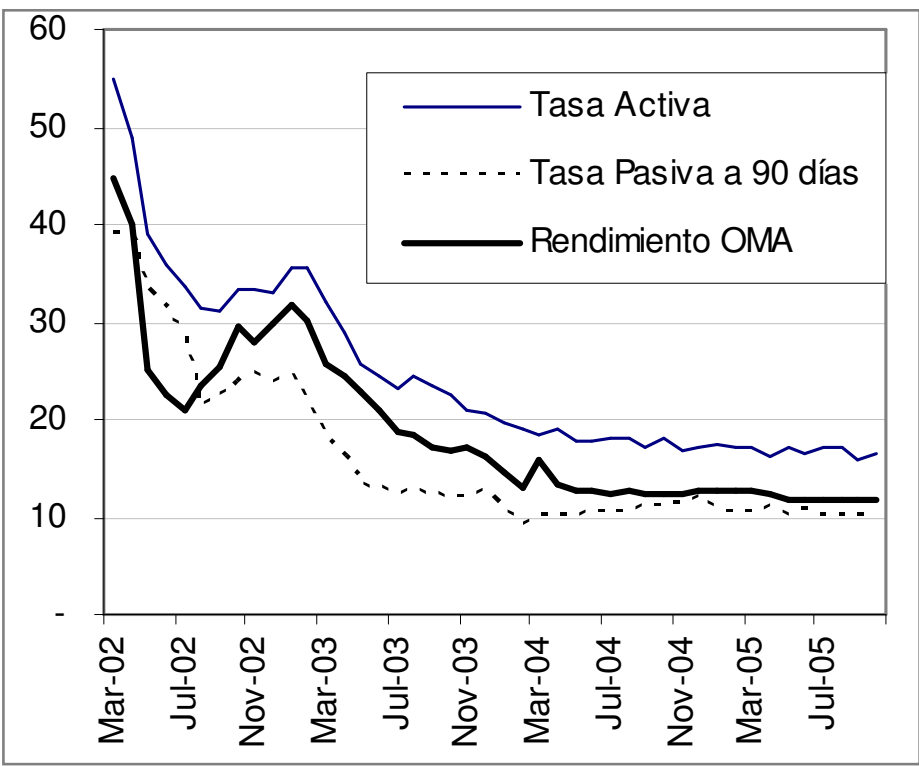

Fuente: Datos del BCV y Cálculos propios.

Figura 18

Tasa de interés activa y stock de crédito real, 2002: 3-2005: 10

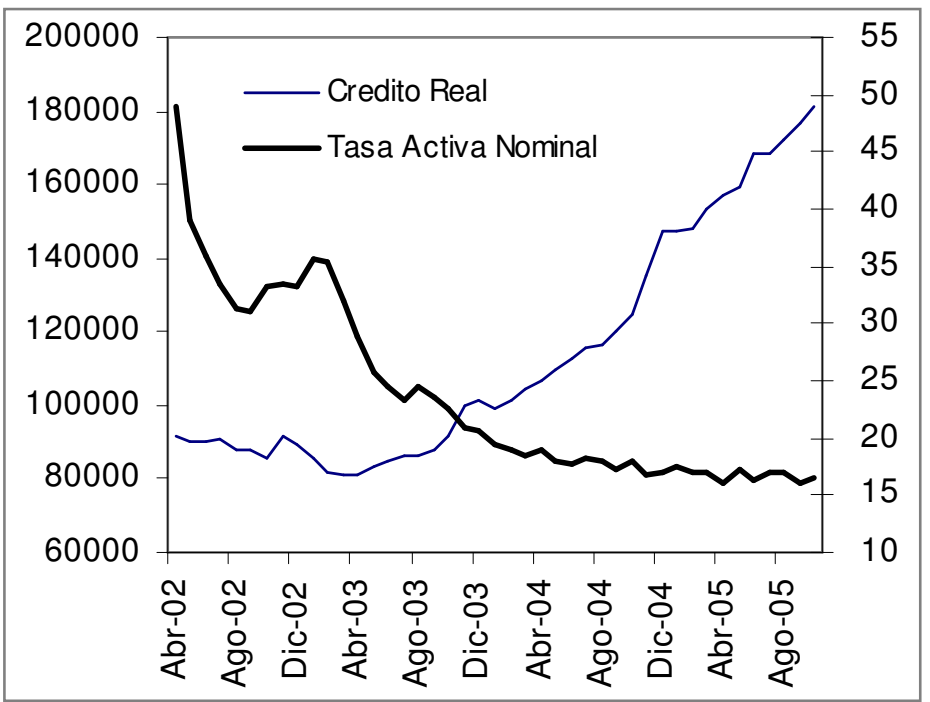

Fuente: BCV, Superintendencia de Bancos y Cálculos propios. 
La identificación del objetivo final de la política monetaria al interior de la 'estrategia monetaria flexible' tampoco es trivial. Al respecto Pagliacci y Ruda (2004, p. 3) señalan nuevamente: "movimientos en las tasas de interés son decididos en función de comportamiento de diversos indicadores, entre los cuales se encuentran la inflación, la actividad económica, los agregados monetarios y el tipo de cambio." Descripciones como estas abren un sin número de interrogantes ¿Son todas y cada una de estas variables objetivos finales de la política monetaria? ¿Cómo es que el Banco Central logra consolidar con un instrumento tal número de objetivos? ¿Pueden efectivamente conciliarse objetivos como los señalados que a menudo lucen como inconsistentes? De hecho Pagliacci y Ruda (2004, p. 4) albergan razonablemente el mismo tipo de dudas cuando señalan que "esta multiplicidad de objetivos implícitamente anunciados por la autoridad monetaria, y posibles cambios en la ponderación relativa, podrían permitir conjeturar que las acciones de política monetaria pudiesen no tener efectos sobre el mercado, debido a que son percibidas como inconsistentes en el tiempo". Dorta y Guerra (2003) intentan despejar estas dudas indicando que el objetivo sigue siendo minimizar el desvío de la inflación respecto de su meta evaluando el comportamiento de la actividad económica, el crecimiento de los agregados monetarios, el gasto público, el tipo de cambio, etc..., variables que presumiblemente serían los argumentos de una función de inflación.

En descargo, bien pudiera señalarse que más que fieles descripciones de lo que es la 'estrategia monetaria flexible', estas referencias podrían ser más bien interpretaciones en torno al proceder actual del BCV. A decir verdad, el Banco Central no ha dado a conocer explícitamente y oficialmente cúal es el proceder de su política monetaria y todas las inferencias antes reseñadas parecen provenir de una propuesta técnica al interior del organismo. ${ }^{28}$ Un reciente informe relativo a la transparencia de la política monetaria en Venezuela, elaborado por Oxford Analytica (2004, p. 408) señala, en este sentido, que el BCV "no ha hecho disponible un documento conciso que explique el marco de la política monetaria y los instrumentos usados para lograr sus objetivos".

En cualquier caso la materia que tiene que ver con el(los) objetivo(s) actual y real de la política monetaria pudiera ser bastante más simple de lo que luce en las interpretaciones arriba señaladas. La Presentación del Mensaje de Fin de Año (2005), por parte del Presidente del Banco Central de Venezuela, parece arrojar mejores luces al respecto. Refiriéndose a la evolución del sector monetario y financiero el Mensaje señala en forma clara y expresa: "La trayectoria de los agregados monetarios expresa los efectos de la política económica con la finalidad de estimular el crecimiento de la economía" (p. 21). Pero también en el informe que presentó el BCV a la Asamblea Nacional en Marzo de 2005 sobre los

(28) Pagliacci y Ruda (2004) hacen referencia a un documento elaborado por el BCV en julio de 2002. 
resultados económicos de 2004, se hace mención explícita al objetivo perseguido por la política monetaria. ${ }^{29}$ La referencia en el informe reza así:

La política monetaria se caracterizó por una expansión en concordancia con el curso de la gestión fiscal. Esta circunstancia fue posible por un ambiente interno de mayor estabilidad y un panorama externo favorables, permitiendo que la expansión de los medios de pago acompañase la generación de producto... No obstante, debido al desfase con el cual la disminución de las tasas de interés promovida durante 2003 afecta la actividad económica, las autoridades decidieron adaptar un enfoque mas cauteloso en la reducción de dicha variable (p. 11).

Analicemos entonces los dos aspectos fundamentales que parecen derivarse de la estrategia de política monetaria que actualmente pone en práctica el $\mathrm{BCV}$. Por un lado, el BCV viene decididamente actuando sobre las tasas de interés de corto plazo, intentando tener algún alcance sobre las tasas de interés del mercado bancario. Por otro, el propósito fundamental de la política monetaria parece estar más asociado a la contribución que pueda darse al crecimiento de la economía (en un contexto en el que muy probablemente la demanda de dinero esté creciendo). ${ }^{30}$ En un marco como éste no hay cabida alguna para el control de los agregados monetarios. No se trata ya de poner en evidencia la erosionada capacidad que tiene el Banco Central para acometer semejante tarea, sencillamente, el procedimiento y objeto de la política monetaria apuntan a otro lugar hoy día. En ese sentido, los retos analíticos y prácticos para el Banco Central son otros. La formula práctica a través de la cual el BCV puede ejercer un control indirecto de la tasas, sin crear distorsiones o desestímulos a la actividad financiera es uno de ellos. El canal de transmisión de las tasas hacia el mercado de crédito puede ser otro (tal relación es digna de ser estudiada como deja ver la Figura 18, al menos para el breve lapso que se inicia en 2002). No deja de ser importante la forma en que se vincula el mercado de crédito con la actividad económica real. Aquí también hay indicios de que la correlación entre el crédito real y la actividad económica es bastante estrecha.

\section{Conclusiones}

En contraste con la enseñanza convencional, los bancos centrales han venido mostrando en los últimos años una tendencia creciente a desistir de los agregados monetarios como objetivos intermedios de política monetaria (De Gregorio, 2003). Las palabras de Charles Bouey, ex-presidente del Banco de

(29) Banco Central de Venezuela (2005) Informe a la Asamblea Nacional sobre los resultados económicos del año 2004, Marzo.

(30) Podría decirse incluso que el BCV ha abandonado su objetivo de precios, pero no estamos en capacidad de hacer tal afirmación. En realidad, gran parte de la responsabilidad ha sido más bien delegada en el ejecutivo quien desarrolla una política administrada de subsidios sectoriales, de control de precios y del tipo de cambio, como estrategia de contención de la inflación. 
Canadá, no pueden ser más elocuentes al respecto: "Nosotros no abandonamos a los agregados monetarios, ellos nos abandonaron". 31 El caso venezolano reciente no parece ser la excepción. Por el contrario, más bien parece demostrar que en una economía abierta y dependiente de un recurso natural, los objetivos intermedios basados en agregados monetarios se ven aun más comprometidos. En general hemos esgrimido varias razones y mostrado algunos indicios para sustentar esta afirmación.

- Las reservas bancarias, y en específico las reservas excedentes, que constituyen un componente esencial del dinero base, exhiben una gran variabilidad. Este es un mercado que está escasamente sujeto a la regulación de la autoridad monetaria.

- La gestión fiscal del gobierno ejerce una influencia decisiva en el comportamiento de la base monetaria, muy a pesar de las acciones reactivas que pueda tomar el Banco Central con sus instrumentos de intervención. La evolución de la base monetaria está muy asociada al comportamiento tendencial del gasto operacional, y el gasto evoluciona al mismo ritmo que el ingreso petrolero externo.

- El multiplicador monetario, del cual forma parte la razón reservas/depósitos, es un parámetro poco estable, poco predecible e impedido de transmitir con precisión las señales de la política del dinero base hacia agregados más amplios.

- La base monetaria también muestra alto grado de endogenidad a los choques externos y se ve severamente afectada por la evolución de las reservas internacionales.

- La estimación de una demanda de dinero, elemento esencial de todo marco de políticas centrado en metas monetarias cuantitativas, es problemática en Venezuela. La lección arrojada por los estudios al respecto para Venezuela indica que no hay seguridad en torno a una relación estable para M2, y para M1, la mayoría de los casos muestra la necesidad de recurrir a la introducción ad-hoc de variables dicotómicas o al relajamiento de la hipótesis de coeficientes constantes.

Aunque hay evidencia suficiente para afirmar que el BCV ha intentado ejercer, a lo largo de los últimos 15 años, alguna regulación o control sobre los agregados, la correlación muy estrecha que hemos encontrado entre la razón saldo de títulos negociados en OMA/base monetaria y la variación de M1, revela el escaso éxito de esta estrategia.

La llamada 'estrategia monetaria flexible', aun con las dificultades interpretativas que derivan de su escasa difusión pública, parece reconocer estas limitaciones y a decir por el proceder de la política monetaria, tanto como por las manifestaciones recientes de sus voceros, el Banco Central luce hoy día más concentrado en el uso de las tasas marcadores de las operaciones de CDs y Repos

(31) Citado en Blinder (1999). 
como variables operativas y en el estimulo de la actividad económica como objetivo último de la política monetaria.

\section{Referencias}

ARREAZA, A.; FERNANDEZ, M. A.; DELGADO, D. La demanda de dinero en Venezuela. Caracas: Banco Central de Venezuela, Vicepresidencia de Estudios, 2000. (Serie Documentos de Trabajo, n. 28).

; AYALA, N.; FERNANDEZ, M. A. Mecanismos de transmisión de la política monetaria en Venezuela. Caracas: Banco Central de Venezuela, Vicepresidencia de Estudios, dic. 2001.

BAGHESTANI, H.; MOTT, T. A cointegration analysis of US money supply process. Journal of Macro Economics, v. 19, p. 269-283, 1997.

BANCO CENTRAL DE VENEZUELA. Informe Económico 1991. Caracas, 1991.

2004. Caracas, mar. 2005.

Informe a la Asamblea Nacional sobre los resultados económicos del año Mensaje de fin de año del presidente del Banco Central de Venezuela. Caracas, dic. 2005.

BANCO MERCANTIL. Informe Banca Comercial y Universal. Segundo Semestre 2005. Caracas, 2006.

BLINDER, A. Central banking in theory and practice. Cambridge: MIT Press, 1999.

BJØRNLAND, H. C. A stable demand for money despite financial crisis: the case of Venezuela. University of Oslo, Department of Economics, 1999. (Memorandum, n. 12/2003).

BRUNNER, K. A schema for the supply theory of money. International Economic Review, p. 79-109, 1961.

; MELTZER, A. H. Some further investigations of demand and supply functions for money. Journal of Finance, p. 240-283, 1964.

CARTAYA, V.; ROO, E.; SÁNCHEZ, G. Demanda de dinero mensual. Caracas: Banco Central de Venezuela, Gerencia de Investigaciones Económicas, sept. 1997. (Serie Documentos de Trabajo, n. 6).

CHRISTIANO, L. J.; EICHENBAUM, M.; EVANS, C. L. Monetary policy shocks: what have we learned and to what end? In: TAYLOR, J. B.; WOODFORD, M. (Ed.). Handbook of macroeconomics. Amsterdam: Elsevier, 1999. v. 1A, p. 65-148.

COPELMAN, M. Financial innovation and the speed of adjustment of money demand: evidence from Bolivia, Israel and Venezuela. Board of Governors of the Federal Reserve System, 1996. (International Finance Discussion Papers, n. 567).

DARBHA, G. Testing for long-run stability - An application to money multiplier in India. Applied Economic Letters, v. 9, p. 33-37, 2002.

DE GREGORIO, J. Mucho dinero y poca inflación: Chile y la evidencia internacional. Cuadernos de Economía, v. 40, p. 716-724, 2003. 
DIAZ, A.; D’EMPAIRE, R. La política monetaria en un proceso de estabilización: el caso Venezolano. Monetaria, v. 15, p. 275-299, 1992.

DIZ, A. Venezuela: aspectos de la medición del impacto fiscal. Revista del Banco Central de Venezuela, n. 1, 1988.

DORTA, M.; GUERRA, J. Relación entre tasas de interés de los instrumentos de política monetaria y las tasas del mercado financiero en Venezuela. Banco Central de Venezuela, Vicepresidencia de Estudios, jul. 2003.

ENGLE, R.; GRANGER, C. Cointegration and error-correction: representation, estimation, and testing. Econometrica, v. 55, p. 251-276, 1987.

EPSTEIN, G. Alternatives to inflation targeting monetary policy for stable and egalitarian growth: a brief research summary. University of Massachusetts at Amherst, 2003. (PERI Working Paper, n. 62).

FLAR. Informe macroeconómico de Venezuela. Boletín Trimestral, Bogotá, jun. 2003.

FORD, J. L.; MORRIS, J. L. The money multiplier, simple sum, divisia and informationdivisia monetray aggregates: cointegration tests for UK. Applied Economics, v. 28, p. 705714, 1996.

GARCIA, G.; RODRIGUEZ, R.; MARCANO, L.; PENFOLD, R.; SÁNCHEZ, G. La sostenibilidad de la política fiscal en Venezuela. Revista BCV, v. 9, 1997.

GOLDMAND; SACHS. Venezuela: unpleasant monetarist arithmetic. New York, 2005. , (Issue, n. 05/23).

GOODHART, C. A. E. Monetary theory and practice. The UK Experience. Macmillan, London, 1984.

GUERRA, J.; PAGLIACCI, C.; ZAVARCE, H. Estrategia monetaria de transición en Venezuela. Banco Central de Venezuela, Vicepresidencia de Estudios, sept. 2002.

HAKKIO, C. S.; RUSH, M. Cointegration: how short is the long run? Journal of International Money and Finance, v. 10, p. 571-581, 1991.

JOHNSON, H. Monetary theory and policy. American Economic Review, v. 52, p. 335384, 1962.

KALDOR, N. The new monetarism. Lloyds Bank Review, v. 97, p. 1-17, 1970.

. The scourge of monetarism. England: Oxford University Press, 1982.

MIRABAL, M. J. Programación y política monetaria en Venezuela, 1989-1998. Cuadernos BCV, Serie Técnica, n. 17, 1999.

MOORE, B. Horizontalists and verticalists: the macroeconomics of credit money. New York: Cambridge University Press, 1988.

A simple model of bank intermediation. Journal of Post Keynesian Economics, v. 12, p. 10-28, 1989.

OLIVO, V. Una estrategia monetaria flexible para la transición hacia un régimen de metas de inflación. Revista BCV, v. 17, p. 55-61, 2003.

OXFORD ANALYTICA. Venezuela. Monetary transparency. Oxford, dic. 2004. 
PÁEZ, K. Demanda de dinero: un enfoque de cointegración. Caso Venezuela 1983: I 1992: IV, Temas de Coyuntura (Instituto de Investigaciones Económicas y Sociales, UCAB, Caracas-Venezuela), v. 31, p. 93-113, 1995.

PALlEY, T. Competing views of the money supply: theory and evidence. Metroeconomica, v. 45, p. 67-88, 1994. 152-180, 2002.

Endogenous money: what it is and why it matters. Metroeconomica, v. 53, p.

PAGLIACCI, C.; RUDA, M. ¿Tienen efectos las acciones de la política monetaria? Un análisis de intencionalidad. BCV. Gerencia de Investigación Económica, 2004. (Serie Documentos de Trabajo, n. 64).

RAMAJO, J. Time-varying parameter error correction models: the demand for money in Venezuela, 1983. I-1994. IV. Applied Economics, v. 22, p. 771-782, 2001.

RASCHE, R.; WILLIAMS, M. The effectiveness of monetary policy. Federal Reserve Bank of St. Louis, 2005. (Working Papers, 0804B).

SACHS, J.; LARRAIN, F. Macroeconomía en la economía global. México: Prentice Hall, 1994.

SÁNCHEZ, G. B. Un modelo de demanda de dinero para Venezuela: 1982-1994. Revista del Banco Central de Venezuela, v. 9, p. 31-51, 1995.

TOBIN, J. Commercial banks as creators of money. In: ESSAYS in economics. Amsterdam: North Holland, 1971. v. 1: Macroeoconomics.

VAEZ-ZADEH, R. Oil wealth and economic behavior: the case of Venezuela 1965-81. IMF Staff Papers, v. 36, Jun. 1989.

VERA, L.; ZAMBRANO, L. Reservas bancarias y gestión de la política monetaria: algunas consideraciones para el caso venezolano. Caracas: Banco Mercantil, 2001. Mimeografado.

WRAY, R. Commercial banks, the Central Bank, and endogenous money. Journal of Post Keynesian Economics, v. 14, p. 282-297, 1992.

ZAMBRANO, L.; RIUTORT, M.; PÁEZ, K. Financiamiento del gasto fiscal, dinámica monetaria e inflación. Caracas: Universidad Católica Andrés Bello, jul. 1995. 